ACCEPTED MANUSCRIPT

\title{
Fabrication of a thick three-dimensional scaffold with an open cellular- like structure using airbrushing and thermal cross-linking of molded short nanofibers
}

To cite this article before publication: Abdalla Abdal-hay et al 2018 Biofabrication in press https://doi.org/10.1088/1758-5090/aae421

\section{Manuscript version: Accepted Manuscript}

Accepted Manuscript is "the version of the article accepted for publication including all changes made as a result of the peer review process, and which may also include the addition to the article by IOP Publishing of a header, an article ID, a cover sheet and/or an 'Accepted

Manuscript' watermark, but excluding any other editing, typesetting or other changes made by IOP Publishing and/or its licensors"

This Accepted Manuscript is (c) 2018 IOP Publishing Ltd.

During the embargo period (the 12 month period from the publication of the Version of Record of this article), the Accepted Manuscript is fully protected by copyright and cannot be reused or reposted elsewhere.

As the Version of Record of this article is going to be / has been published on a subscription basis, this Accepted Manuscript is available for reuse under a CC BY-NC-ND 3.0 licence after the 12 month embargo period.

After the embargo period, everyone is permitted to use copy and redistribute this article for non-commercial purposes only, provided that they adhere to all the terms of the licence https://creativecommons.org/licences/by-nc-nd/3.0

Although reasonable endeavours have been taken to obtain all necessary permissions from third parties to include their copyrighted content within this article, their full citation and copyright line may not be present in this Accepted Manuscript version. Before using any content from this article, please refer to the Version of Record on IOPscience once published for full citation and copyright details, as permissions will likely be required. All third party content is fully copyright protected, unless specifically stated otherwise in the figure caption in the Version of Record.

View the article online for updates and enhancements. 
Fabrication of a Thick Three-Dimensional Scaffold with an Open Cellular-Like

\section{Structure Using Airbrushing and Thermal Cross-Linking of Molded Short Nanofibers}

Abdalla Abdal-hay ${ }^{1}$, Stephen Hamlet $^{2}$, Saso Ivanovski ${ }^{1 *}$

${ }^{1}$ School of Dentistry, The University of Queensland, Oral Health Centre, 288 Herston Rd, QLD 4006, Australia,

${ }^{2}$ Menzies Health Institute, Griffith University, Gold Coast Campus, Parklands Drive, QLD 4222, Australia.

*Corresponding Author:

$$
\text { E-mail: s.ivanovski@uq.edu.au (S. Ivanovski) }
$$

Tel: +61733658064

Keywords: Airbrushing; Polycaprolactone (PCL); Bone Tissue Engineering; Biodegradable Composite Materials; Three-dimensional; Cell infiltration 


\begin{abstract}
:
Nanoscale fibers mimicking the extracellular matrix of natural tissue can be produced by conventional electrospinning, but this approach results in two-dimensional thin dense fibrous mats which can hinder effective cell infiltration. The aim of the present study was to design a thick, three-dimensional (3D) cylindrical scaffold with an open pore structure assembled from short polycaprolactone (PCL) fibers using a facile airbrushing approạch. In addition, magnesium-particles were incorporated into the PCL solution to both enhance the mechanical properties of the scaffold and stimulate cellular activity following cell seeding. Separated short composite airbrushed fibers were assembled into a 3D cylindrical structure by cold-press molding and thermal crosslinking. The microstructure, chemical composition, porosity and thermal properties were subsequently investigated, along with changes in mechanical performance following immersion in PBS for 60 days. The results showed that the assembled 3D fibrous $10 \mathrm{~mm}$ thick cylindrical matrix had an interconnected fibrous network structure with 31.5-60\% porosity. Encapsulation of the Mg particles into the 3D assembled fibrous scaffold enhanced the mechanical properties of the plain PCL scaffolds. The results also demonstrated controlled release of $\mathrm{Mg}$ ions into the PBS media for up to 60 days, as evaluated by changes in $\mathrm{Mg}$ ion concentration and $\mathrm{pH}$ of the media. In addition, the 3D fibrous assembled matrix was shown to support human osteoblast-like cell adhesion, proliferation and penetration. The results suggest that this novel fabrication method of biodegradable thick 3D scaffolds with an open pore structure is promising for the production of a new generation of 3D scaffolds for tissue regeneration applications.
\end{abstract}




\section{Introduction}

In recent years, the use of synthetic implants and tissue grafts has been supplanted by tissue engineering approaches that use biocompatible, degradable and porous scaffolds integrated with cells or bioactive molecules to regenerate tissues [1-4]. Physically, these scaffolds should mimic the hierarchical structure of native tissues, i.e. a three-dimensional (3D) structure that can range in scale from $1 \mu \mathrm{m}$ to $10 \mathrm{~mm}$, with a biomimetic extracellular matrix (ECM) architecture [5-7]. As such, there has been considerable research focus on designing 3D porous scaffolds with fibrous architecture that can mimic the native ECM structure, biological performance and mechanical support [6, 8-10]. For tissue engineering applications, a 3D ECMmimicking structure is often superior compared with traditional $2 \mathrm{D}$ structures because the $3 \mathrm{D}$ scaffold offers a more favorable environment for cell-cell interactions, cell migration and cell morphogenesis, which are important for functional tissue regeneration [2, 8]. Indeed, 3D scaffolds with a larger tissue volume and open pore structure are increasingly being investigated for tissue engineering applications $[5,11,12]$. However, the fabrication of such large volume 3D scaffolds remains a major challenge $[4,7,13]$.

To overcome this obstacle, different fabrication techniques have been devised to create scaffolds for tissue engineered constructs [14], such as solvent casting and particulate leaching, membrane lamination, melt molding, thermally induced phase separation, gas foaming and electrospinning. None of these conventional techniques however has allowed researchers to build thick 3D scaffolds (up to $10 \mathrm{~mm}$ ) with a completely open and interconnected pore network. Some attempts however have been made to design thick 3D scaffolds with cellular-like structure from assembled electrospun fibers. Si et al [2] assembled polyacrylonitrile (PAN) broken fibers into a 3D structure by combining electrospinning and freeze-drying techniques with chemical crosslinking, whereas another study applied the same approach using gelatin and polylactic acid (PLA) as assembled short composite fibers [15]. 
Other research groups have attempted to fabricate sonicated chitosan nanofiber mats with enlarged porosity [16], however only 3 -fold increase in the original thickness was achievable. These attempts also have several drawbacks. Besides being complex and time consuming, only brittle/ tough electrospun fibers can be used which are easily broken down. Further, toxic chemicals are often used for cross-linking the assembled fibers and the resultant scaffolds often lack mechanical integrity. Therefore, it is imperative to develop a suitable, ropust methodology for creating 3D scaffolds consisting of an open-pore, interconnected fibrous network, with a hierarchical architecture and controlled thickness that is capable after cell seeding and proliferation of supporting cellular infiltration, organization and uniform cellular distribution.

Recently, airbrushing (also referred to as solution spraying, blow spinning or air jet spinning) has been used to fabricate nanofibers by stretching a polymer solution through a small orifice diameter $(<350 \mu \mathrm{m})$ into fibers under compressed gas [11, 17-20]. Several research groups including ours [20-23] have shown that an airbrushing spinning approach was safer compared to electrospinning that doesn't require a high potential voltage. Airbrushing is also 10-fold faster and 100-fold less expensive to set-up [21], and is able to deposit nanofibers onto a broader range of targets compared to electrospinning. Short and loosely packed nanofibers can be obtained using this approach [21,22] compared to densely/ tightly stacked and entangled fibers produced by electrospinning [16]. Furthermore, for composite fibers, airbrushing has been accepted as a suitable approach in the fabrication of polymer fibers loaded with different inorganic particles [22-24]. Hence, in this study we aimed to exploit the features of a high production rate $(15 \mathrm{ml} / \mathrm{min}[22])$ and short nanofiber formation (see the attached video supplementary material) using airbrushing to produce short and separated fibers which could be assembled directly without further processing into a porous 3D structured fibrous scaffold with a large thickness (up to10 mm). 
We have designed for the first time a fibrous cylindrical matrix made of elastic polymer (polycaprolactone, PCL) short fibers and magnesium micro-particles. PCL is an FDA approved biodegradable polymer that has been widely used in tissue regeneration [4, 25-27]. Among the various bioresorbable polymers used for biomedical applications, it has an unusually low glass transition temperature $\left(-60^{\circ} \mathrm{C}\right)$. It exists in a rubbery state at room temperature and has a low melting temperature of $60{ }^{\circ} \mathrm{C}$. Another characteristic property of PCL is its high thermal stability. Hence the challenge in the present study was to use PCL as a flexible material to build a thick 3D fibrous scaffold from short spun fibers using an airbrushing approach and thermal crosslinking of the assembled fibers. In/addition, the incorporation of magnesium $(\mathrm{Mg})$ particles into a polymer matrix has been shown to alter the mechanical properties and enhance the cellular response to the composites [28,29]. Magnesium, the second most abundant intracellular cation, is a biodegradable metallic material essential to bone development [30]. Studies that have incorporated particles of metallic Mg within polymer fiber matrices assembled together into 3D architectures are scarce and do not consider in vitro degradation and the cellular response. Due to PCL's semi-crystalline nature, its degradation rate is slow and dependent on the molecular weight [26]. Hence, incorporation of Mg into the PCL polymer fiber matrix is a sound strategy to diminish the rapid release of $\mathrm{Mg}$ particles [28].

With the goal of developing millimeter-scale 3D thick scaffold with an open interconnected network structure that can mimic the architecture of ECM using a cost-effective and simple strategy, the present study fabricated composite PCL-Mg fibers using airbrushing, which were then assembled into a thick $(\sim 3$ and $10 \mathrm{~mm}) 3 \mathrm{D}$ architecture using thermal crosslinking. Subsequently, the mechanical properties of the composites and the in vitro release of $\mathrm{Mg}$ ions were determined, along with the attachment, proliferation and infiltration of human osteoblasts seeded onto the assembled fibrous 3-D cylindrical scaffolds.

\section{Materials and Methods}

\subsection{Materials}


One plain PCL and two PCL/Mg-particle composite fibrous scaffold groups were fabricated. The composite scaffolds were prepared by dispersing magnesium particles into a PCL matrix (Sigma Aldrich catalog no. 44,074-4). Irregular flake-like Mg particles (Mg density: $1.74 \mathrm{~g} \mathrm{~cm}^{-3}$ ) with particle size ranging from 50 to $125 \mu \mathrm{m}$ and a length to width ratio of 1.8:1 and chemical composition of $99 \% ; 0.05 \% \mathrm{Cu}, \mathrm{Fe}, \mathrm{Si}$ and $\mathrm{Al} ; 0.001 \%$ Ni were also purchased from Sigma-Aldrich (catalog no. 7439-95-4). Figure S1 (supporting information) shows the X-ray structure profile and SEM image of the as-received Mg-particles. Analytical grade chloroform and ethanol for preparation of the PCL solvent were supplied by Junsei Chemical Co., Japan. Dulbecco's modified Eagle's medium (DMEM, Gibco, CA, USA), Foetal Bovine Serum (Life Technologies, Pty Ltd), Penicillin-Streptomycin, MEM NonEssential Amino Acids Solution (Gibco, St. Louis, MO, USA) weré used for cell culture media preparation.

\subsection{Preparation of assembled $3 D$ fibrous scaffold}

PCL beads $\left(\sim 3 \mathrm{~mm}\right.$ with number-average molecular weight $\left(\mathrm{M}_{\mathrm{n}}\right)$ of 80,000 (GPC), $60{ }^{\circ} \mathrm{C}$ melting point and density of $1.145 \mathrm{~g} / \mathrm{mL}$ at $25^{\circ} \mathrm{C}$ ) were dissolved in $7 \mathrm{wt} \%$ chloroform at room temperature with continuous vigorous stirring for several hours until a transparent solution was obtained. Our previous studies have shown that 7 wt. \% PCL concentration is highly suitable for creating micro/nano-fibers by means of the airbrushing approach [3]. Both 5 and $8 \%$ in mass of Mg-particles were dispersed in the PCL solution at room temperature.

Plain PCL and PCL/Mg particles composite solutions were fabricated using a modified airbrushing method [3, 22]. The airbrushed system consisted of an inner and a concentric outer nozzle (Fig. 1) and the polymer solution was ejected through the inner nozzle and high velocity gas (compressed air) passed through the concentric outer nozzle. The PCL and PCL/Mg particles composite solutions were injected into a gravity fed cup (Fig. 1) of a double action/internal mixing airbrush spraying device (Airbrush-Pistole AB 430 Düsen, 
Conrad, Germany) at $30 \%$ humidity. The airbrush system has a $350 \mu \mathrm{m}$ output nozzle diameter and was connected to a cylinder of compressed medical grade air (450 kPa) equipped with a pressure regulator. Based on our previous experience in using airbrushing, the working distance between the airbrush outlet nozzle and a flat collector was set at $75 \mathrm{~cm}$ to provide enough time for solvent evaporation from the spun fibers before deposition on the collector.

The airbrushed spinning process was performed inside a ducted fume-hood in a PC2 laboratory according to the University of Queensland health and safety regulations which meet current national and international standards. Fume hoods are inspected and tested annually to assess performance standards. For further personal protection during the fabrication process, a AS/NZS1716 rated P2 particle respiratory filter mask capable of filtering $0.3 \mu \mathrm{m}$ particles was used. P2 masks are suitable to capture mechanically and thermally generated particles in the sub-micron range.

The collected composite fibers were dried at $40^{\circ} \mathrm{C}$ in a vacuum oven for 72 hours before separation in $100 \%$ ethanol for $5 \mathrm{~min}$ at room temperature. Afterwards, the separated fibers were kept dry at room temperature before placing into a cold-press molding machine (Carver \#3912) containing a mold with holes $10 \mathrm{~mm}$ in diameter to fit into the bottom of 48 well cell culture plates. Compression was then gradually increased to $300 \mathrm{kPa}$. Subsequently, the molds were placed in a $55^{\circ} \mathrm{C}$ oven for $10 \mathrm{~min}$ to allow homogenization. Afterwards, the molds were cooled to ambient temperature at a fast rate and the specimens demolded. Specimens of 10 and $3 \mathrm{~mm}$ heights for the mechanical and in vitro studies were prepared. A schematic diagram of the preparation method and 2D specimens' morphology are shown in Figure 1.

\subsection{Characterization}

2.3.1.Scanning electron microscopy (SEM) 
The surfaces of the as-spun fibers, 3D molded fibers and the flexural fracture (in a liquid nitrogen) surfaces of the molded samples were coated with gold sputtered nanoparticles $(\sim 10$ $\mathrm{nm}$ ) for 2 min to avoid charging during SEM observation and then examined using a scanning electron microscope (SEM, Jeol JSM-6400, Japan).

\subsubsection{Porosity measurements of assembled 3D fibrous scaffold}

The height and diameter of the plain and PCL/Mg-particle cylindrical fibrous matrix were accurately measured using a digital micro-meter (Coolant Proof IP65-MX 2 Mitutoyo) with a precision of $\pm 1.0 \mu \mathrm{m}$, the porosity of the 3D fibrous scaffolds were calculated using the following equations according to the previous study by Lee et al 2011 [31]:

The final density of 3D composite scaffold $\left(\mathrm{g} / \mathrm{cm}^{3}\right)=$

$\overline{\text { Scaffold height }(\mathrm{cm}) \times \text { Scaffold cross section area }\left(\mathrm{cm}^{2}\right)}$

Porosity $(\%)=1-\frac{\text { Density of scaffold }\left(\mathrm{g} / \mathrm{cm}^{3}\right)}{\text { Therotical density of used materials }\left(\mathrm{g} / \mathrm{cm}^{3}\right)}$

The mass of $3 \mathrm{D}$ scaffold was measured using a balance with an accuracy of $\pm 0.1 \mathrm{mg}$. The theoretical density of the composites was measured by the rule of mixture using the theoretical density of Mg and PCL.

\subsubsection{Thermal analysis}

Thermogravimetric analysis (TGA) of the plain and PCL/Mg-particle composite cylindrical matrices was performed (TGAQ50 instrument) from room temperature to $600^{\circ} \mathrm{C}$ at a heating rate of $10^{\circ} \mathrm{C} / \mathrm{min}$ under nitrogen gas flowing at $60 \mathrm{~mL} / \mathrm{min}$. About $15-25 \mathrm{mg}$ of sample was used in each test. Thermal analysis of the as-received, untreated and thermally treated PCL polymer was analyzed using a differential scanning calorimeter (DSC, Q20V24.9) equipped with a liquid nitrogen cooling accessory. The samples were placed in aluminum pans under a nitrogen atmosphere, heated from -80 to $110^{\circ} \mathrm{C}$, cooled to room temperature, and then heated to $110^{\circ} \mathrm{C}$ and maintained for $1 \mathrm{~min}$ to ensure the complete melting of the PCL crystals. The samples were subsequently quenched to $-80{ }^{\circ} \mathrm{C}$ at the same rate of $10{ }^{\circ} \mathrm{C} / \mathrm{min}$ and then 
heated again from $-80{ }^{\circ} \mathrm{C}$ to $110{ }^{\circ} \mathrm{C}$ at the same heating rate. The data was collected from the second cycle. The glass transition temperatures $(\mathrm{Tg})$ were determined from the inflection point of the heat flow curve. The thermograms were recorded at a rate of $10{ }^{\circ} \mathrm{C} \min ^{-1}$. The melting points and the heat of fusion (the melting heat) were determined to calculate the polymer crystallinity. The crystallinity was calculated as described elsewhere [4, 32-34]. First and second independent cycles of heating and cooling runs were initiated in which the first cycle was able to eliminate the polymer heat history. With a reference point of $136 \mathrm{~J} / \mathrm{g}$ for $100 \%$ crystalline PCL [34], the degree of crystallinity Xc \% of the polymer scaffold was determined. Of note, the composite scaffolds containing Mg particles have less PCL contribution compared to plain PCL scaffolds. Hence, heat of fusion of the composite= $\frac{\text { heat of fusion of plain PCL } \times 100}{\text { PCL concentration in the composite matrix }}$

\subsubsection{X-ray diffraction}

The phase composition of the 3D molded fibrous scaffold was characterized using an Xray diffractometer (XRD; Rigaku, Japan); the XRD studies used an X'Pert XRD and a Cu Ka $\left(\mathrm{k}=1.54056 \mathrm{~A}^{\circ}\right)$ radiation over $2 \mathrm{~h}$, with 2 -thetain the range of $5-60^{\circ}$. The operating voltage and current used were $40 \mathrm{kV}$ and $30 \mathrm{~mA}$, respectively, with a beam size of $20 \mu \mathrm{m}$.

\subsubsection{Infrared analysis}

Infrared spectra of plain PCL and composite 3D fibrous samples were recorded using a Fourier transform infrared (FTIR) spectrometer (Perkin-Elmer) in a wave length $4000-400 \mathrm{~cm}^{-}$ ${ }^{1}$. The FTIR spectrum was run in transmittance mode.

\subsection{In vitro degradation in PBS media}

The cylindrical assembled fibrous scaffolds of plain PCL and PCL/Mg composites with $3 \mathrm{~mm}$ height were immersed separately in $30 \mathrm{ml}$ of phosphate buffered saline (PBS, $\mathrm{pH}=7.2$ ) solution in falcon tubes and placed in an incubator for 3, 7, 14, 30, 45 and 60 days. The samples were stored in an oven at $37{ }^{\circ} \mathrm{C}$. Three samples were analyzed at each time point using 
inductively-coupled plasma optical emission spectrometry (ICP-OES, Vista-MPXCCD Simultaneous ICP-OES) to determine the ion concentrations and establish the correlation between ion dissolution and time. $\mathrm{pH}$ values were also measured using a $\mathrm{pH}$ meter. The corrosion rate was determined by measuring the weight loss from each sample. The surface and morphology of the plain PCL and PCL/Mg-particle composites after the immersion test for 60 days were examined by the SEM.

\subsection{Mechanical properties}

Compression test measurements of the $10 \mathrm{~mm}$ height plain PCL and composites samples were conducted with a $2000 \mathrm{~N}$ load cell mechanical tester (Computerized Instron Universal Testing Instrument model 4206) in air before and after immersion in PBS for 60 days. The testing was done in a standard laboratory atmosphere. The samples that were reported by the tests were conducted at an across-head speed of $1.0 \mathrm{~mm} / \mathrm{min}$. The two surfaces of cylindrical assembled fibrous scaffolds were machined by using SiC paper to 1000 grade to assure the essential condition of parallel plane bases for compression tests. The compression strength (CS) was evaluated using the load-displacement curve with the peak load from the curve and the initial cross-sectional area of the sample. The compression tests were performed according to the ASTM D695-08 protocol and the compressive moduli were evaluated after the compression test. The composite samples underwent standard compression tests until the next constant maximum stress was reached. A minimum of three specimens for each sample were tested and then the mean values and standard deviations were calculated.

\subsection{Osteoblast culture}

Plain PCL and PCL/Mg composite assembled 3D fibrous scaffolds in disc form $(\sim 10$ $\mathrm{mm}$ diameter and $3 \mathrm{~mm}$ height) were inserted into 48-well tissue culture plates. Prior to cell seeding, a thin layer $(\sim 0.3 \mu \mathrm{m})$ of the sample's top surface which was in direct contact to the punch surface was removed. Scaffolds were sterilized two times in $70 \%(\mathrm{v} / \mathrm{v})$ ethanol and kept 
overnight inside the cell hood to completely dry, and subsequently UV light was applied to the scaffolds for $30 \mathrm{~min}$ on each surface before cell seeding.

Alveolar-bone derived human osteoblast (OB) cells were explanted from 20-25 years old healthy subjects (Ethical approval for the use of this redundant tissue was attained through the Griffith University Human Research Ethics Committee, DOH/17/7/HREC), The primary cell cultures were established as described in previous publications [35, 36]. In addition, the previous study by Haase et.al [36] has demonstrated that the extracted cells act as osteoblasts. The isolated cells were cultured at $37{ }^{\circ} \mathrm{C}$ with $5 \%$ by volume $\mathrm{CO}_{2}$, in $\mathrm{DMEM}$ supplemented with 10\% FBS, Penicillin-Streptomycin (10,000 U/mL) and MEM Non-Essential Amino Acids Solution $(10 \mathrm{U} / \mathrm{ml})$. Primary osteoblasts were passaged at $80 \%$ confluency and dissociated with $0.25 \%$ trypsin. Cells (passage 6) were seeded onto the scaffolds in 48-well plates at 25,000 cells/well. The seeded scaffolds were left untouched for $2 \mathrm{~h}$ to allow for cell attachment. 0.4 $\mathrm{mL}$ of culture medium was then added to each well so that the scaffolds were fully submerged. After $24 \mathrm{~h}$, medium was replaced with fresh medium and it was changed twice per week and cells cultured for 1, 4, 7 and 14 days.

\subsection{Fluorescence imaging}

Cells on scaffolds were fixed with $4 \%$ paraformaldehyde v/v in PBS for $30 \mathrm{~min}$ at room temperature, washed (PBS), permeabilized ( $0.2 \%$ by mass Triton X-100 for 3-5 min) and rinsed three times with PBS. Cellular actin was subsequently stained for 90 min with fluorescent 532phalloidin conjugate (AAT Bioquest, USA). Cell nuclei were visualized by staining with fluorescent 4',6-diamidino-2-phenylindole (DAPI, Vector Laboratories, Burlingame, CA, USA) dye for $30 \mathrm{~min}$ at room temperature. After staining, scaffolds were washed with PBS twice, placed on glass slides and imaged by confocal laser scanning microscopy (Nikon, Eclipse- Ti, U.S.A) to visualize the morphology of actin fibers and nuclei of OB cells on the scaffolds using $10 \times / 0.13$ and $20 \times / 0.45$ objectives. OBs were also imaged by the confocal 
microscope using a 10×/1.4 oil immersion objective with a $4 \mu \mathrm{m}$ Z-step size. To assess cell shape, confocal fluorescence Z-stacks of OBs cultured for 7 days on the 3D scaffolds were analyzed using ImageJ software (NIH). For assessment of cell spread area, Z-stacks (4 $\mu \mathrm{m}$ zstep size) were projected as 2D images and converted into binary images, and subsequently ImageJ was used to measure cell spread area. For cell volume, Z-stacks were thresholded, cell outlines were created, and the ImageJ plugin "3D Object Counter" was used to calculate cell volumes. Fluorescence microscopy was also used to observe cell morphology on the scaffolds after 7 days of culture.

\subsection{Osteoblast proliferation and viability}

To assess osteoblast proliferation, cellular DNA quantification was determined by picogreen assay. The picrogreen assay was run according to the manufacture's protocol. The remaining media was removed and washed with PBS. Then the scaffold materials containing cells were transferred into $1.5 \mathrm{~mL}$ eppendorf tubes and digested with $500 \mathrm{ml}$ of Proteinase $\mathrm{K}$ (Invitrogen) (Proteinase K/phosphate buffered EDTA (PBE) $0.5 \mathrm{mg} / \mathrm{ml}$ ). The frozen samples at $-80{ }^{\circ} \mathrm{C}$ for $48 \mathrm{hr}$, were placed in $1.5 \mathrm{ml}$ eppendorf tubes containing $500 \mathrm{~mL}$ of Proteinase $\mathrm{K}$ (Merck) (Proteinase K/phosphate buffered EDTA (PBE) $0.5 \mathrm{mg} / \mathrm{mL}$ ), at $60{ }^{\circ} \mathrm{C}$ for at least $24 \mathrm{~h}$ until no visible scaffold material remained. The cells on the tissue culture plate were also incubated with Proteinase $\mathrm{K}$ in $37^{\circ} \mathrm{C}$ for $24 \mathrm{~h}$. To calculate the final DNA content of the scaffold, a standard curve of known DNA ( $\lambda$ DNA) concentrations ranging from $1 \mathrm{ng} / \mathrm{mL}$ to 1 $\mu \mathrm{g} / \mathrm{mL}$ was obtained by diluting $\lambda$ DNA stock solution into 1x TE buffer (Invitrogen), in concentrations of $1 \mathrm{ng} / \mathrm{mL}, 10 \mathrm{ng} / \mathrm{mL}, 100 \mathrm{ng} / \mathrm{ml}$ and $1 \mu \mathrm{g} / \mathrm{ml}$. Then, $100 \mu \mathrm{l}$ of the purified supernatant and the diluted standard DNA were aliquoted in triplicate into black 96-well plates, and $100 \mu \mathrm{L}$ of PicoGreen (P11496, Invitrogen) working solution was added to obtain a total volume of $200 \mu \mathrm{l}$. After $5 \mathrm{~min}$ incubation in the dark, the fluorescence (excitation $485 \mathrm{~nm}$, 
emission $520 \mathrm{~nm}$ ) was measured using a fluorescence plate reader. For the DNA analyses, 4 biological replicates were used.

Cell viability was assessed by determining metabolic activity, An Alamar Blue assay was used in the present study according to the manufacturer's instructions 7 and 14 days after cell seeding. The plain PCL and PCL/Mg-particle composite (8 wt. \% of $\mathrm{Mg}$ ) 3D fibrous scaffolds were removed from the incubator and rinsed with phosphate-buffered saline two times. After incubation the cultured scaffolds in $10 \% \mathrm{v} / \mathrm{v}$ of alamarBlue in DMEM complete fresh media as a working solution for $120 \mathrm{~min}$ at $37^{\circ} \mathrm{C}, 100 \mu \mathrm{l}$ of the alamarBlue solution was transferred to a 96-well plate in triplicate for each of the samples and read on the fluorescence plate reader (Cytofluor, Perceptive Biosystems) at $530 \mathrm{~nm}$ excitation, $590 \mathrm{~nm}$ emission. Six measurements were carried out for each sample group. Three groups were tested: a) a 3D assembled composite fibrous scaffold $=\%$ viability measured from cells seeded onto PCL/Mgparticles at 8 wt. $\%$ of $\mathrm{Mg}$ loading, b) a 3D assembled plain fibrous scaffold $=\%$ viability measured from cells seeded onto PCL and c) Tissue culture plastic (TCP) $=\%$ viability measured from cells seeded onto standard tissue/culture plastic surface (seeded into one well of 48 well plate).

\subsection{Statistical Analysis}

All data are shown as means with standard deviation. The standard deviation (S.D.) is the same as the "combined standard uncertainty of the mean" for the purposes of this work. To test for statistically significant differences, a t-test was used for pairwise comparisons $(\mathrm{p}<$ 0.05) and one-way analysis of variance (ANOVA) with Tukey's post hoc testing was used for comparison of 3 or more treatments $(\mathrm{p}<0.05)$.

\section{Results and Discussion}

\subsection{Characterization of assembled 3D fibrous scaffold}


Airbrushing parameters, such as concentration, compressed air pressure, distance between the collector and the exit nozzle were optimized based on our previous publications $[17,18,22,24]$. The polymer concentration used was controlled at $7 \mathrm{wt} . \%$, as a higher polymer concentration clogged the airbrush while lower polymer concentrations resulted in mats that were gummy, did not dry and did not form nanofibers, rather producing beads instead of nanofibers. It has been suggested that decreasing or increasing the distance between the collector and the outlet nozzle has a significant influence on the formation of interconnected or stray fibers at specific polymer concentrations [20]. A pilot assessment carried out in this study found that using a 7 wt. \% PCL concentration set $75 \mathrm{~cm}$ from the collector, loosely packed nanoscale (120 to $550 \mathrm{~nm}, \mathrm{n}=50$ ) fibers could be obtained as shown in Figure 3a. In addition, the attached video provided as supplementary information (V.S1) shows the formation of short fibers during the fabrication process. This confirms that, in general, the ejected fibers from the airbrush nozzle are micrometer to millimeter scale in length (V. S1 and Fig. S2).

For the composite scaffolds, figure $2 \mathrm{~b}$ shows $\mathrm{Mg}$ particles were incorporated within the PCL. At high magnification, it can be observed that the Mg particle was fully covered with a thin porous layer of PCL (Fig. 2c). The chemical composition of the PCL/Mg-particles composite fibers, which is composed of $\mathrm{C}, \mathrm{O}$ and $\mathrm{Mg}$, is shown in Fig $2 \mathrm{~d}$.

Ideally, scaffolds need to assemble into an open 3D fibrous architecture where the fibers bond with each other to form interconnected networks rather than simply stacking together. Figure 3a shows that homogenization of the spun short fibers in ethanol for 10 min allowed 3D assembly by cold-pressing. The short and loosely packed nanofibers (as a result of airbrushing) within the assembled 3D structures did not require any further preparation, in contract to what is observed with nanofibers produced by electrospinning [13]. Thermal bonding at $55{ }^{\circ} \mathrm{C}$, rather than simply stacking the fibers $[37,38]$ was utilized, as no fiber 
bonding was induced below $55^{\circ} \mathrm{C}$ and the fibers were completely melted at temperatures above $55^{\circ} \mathrm{C}$ (Fig. 3b).

Figure 4(a-d) depicts the SEM morphology of the bottom, upper, side-view and crosssection of the 3D scaffold. At the outer surfaces, fused bonded fibers were created due to direct contact with the metal punch and die wall surfaces. In the cross-sectional view, the fiber diameter was shown not to be significantly different between the untreated and thermally bonded PCL fibers. Moreover structural instability, such as dimensional shrinkage, did not occur as a result of the thermal treatment (data not shown).

For the PCL/Mg composite 3D scaffold, the thin PCL layer that was formed on the Mgparticles during the spraying process (Fig. $2 b \&$ c) was melted and contiguous fibers can be observed which are partially fused to the Mg-particles, as shown in Figure 4(e \& f). This is likely due to the thermal properties of the Mg metal, including specific heat capacity, thermal diffusivity and thermal conductivity which is markedly different compared to PCL, which is a thermally isolated material $[26,39]$. This therefore contributes to faster fusing/melting of the surrounded polymer molecules/fibers to metallic components such as Mg-particles, as well as the upper and lower parts of the mold.

The mean porosities of the plain PCL, 5 wt. $\%$ and 8 wt. $\% \mathrm{Mg}$ composite assembled 3D structures were $62 \pm 4.3,40 \pm 5.11$ and $31.5 \pm 3.41 \%$, respectively. An effect of Mg-particles on the porosity of interconnected architecture could be observed (Fig. 4 of Mg cross-section), which was possibly due to the large size of the Mg-particles $(50-125 \mu \mathrm{m})$ and fiber fusion in the scaffold. In addition, the pore size of the plain PCL 3D fibrous scaffold ranged from 11 to $20 \mu \mathrm{m}$ which was significantly $(\mathrm{P}<0.05)$ higher than that of PCL scaffolds loaded with Mgparticles $(3$ to $10 \mu \mathrm{m})$. The pore diameter was also not uniform, as shown in Figure 4 . These differences in porosity measurements were supported by the SEM results which showed that 
plain PCL nanofiber 3D scaffolds had a larger pore size, while the composite 3D fibrous scaffold loaded with Mg-particles had a smaller pore size.

\subsection{Thermal properties}

TGA and derivative thermogravimetric (DTG) curves were used to determine weight loss and to illustrate the thermal properties of the scaffolds, as shown in Figure $5(\mathrm{a} \& \mathrm{~b})$. The results show that the decomposition temperature of PCL composite scaffolds loaded with metallic $\mathrm{Mg}$ particles is lower than that of plain PCL. The plain, 5 and 8 wt. \% composite scaffolds decomposed at temperatures of 396.6, 328 and $324^{\circ} \mathrm{C}$, respectively (Fig. 5). Hence, the thermal stability of the PCL/Mg composites was reduced compared with the plain PCL 3D scaffolds. The DTG curves (Fig. 5b) also indicate that the maximal weight loss rate shifted from $419.5^{\circ} \mathrm{C}$ (plain PCL) to $350{ }^{\circ} \mathrm{C}(8 \mathrm{wt} . \% \mathrm{Mg})$. A possible reason for the lowered thermal stability of the composite 3-D scaffolds is that Mg particles have a higher thermal conductivity than the PCL polymer, making it easier for thermal degradation to occur from the PCL surface [33]. Thus the Mg particle content affects the thermal degradation process of the PCL polymer making it more sensitive to heat. These results are in a good agreement with the previous intensive study by Fernández et.al [34].

The results obtained from the differential scanning calorimetry (DSC) thermograms show a single melting endotherm (Table 1) which indicates that the PCL is semi-crystalline. All PCL based scaffolds showed similar melting temperatures $\left(\sim 57^{\circ} \mathrm{C}\right)$, indicating that the fabrication process had no effect on the melting temperature. The melting temperature $\left(T_{m}\right)$ and the change of melting of heat $\left(\Delta \mathrm{H}_{\mathrm{m}}\right.$, heat of fusion) were obtained from the second heating thermograms while the crystallization temperature $\left(\mathrm{T}_{\mathrm{c}}\right)$ was determined from the cooling thermograms. Plain PCL had the lowest crystallization temperature of $28.85{ }^{\circ} \mathrm{C}$ compared to the composite 3-D scaffolds. The crystallization temperature was increased from pure PCL to the PCL/Mg composites at $8 \mathrm{wt} . \%$, whose crystallization temperature was $32.38{ }^{\circ} \mathrm{C}$. The 
highest crystallinity (58.67\%) was found in the 8 wt. \% scaffold whereas the lowest crystallinity $(47.83 \%)$ was found in the plain PCL scaffold. 5 wt. $\%$ had about $5 \%$ lower crystallinity as compared to the 8 wt. $\%$ of $\mathrm{Mg}$ composite scaffold. This shows that incorporation of $\mathrm{Mg}$ particles is able to enhance the crystallization of PCL molecules. This is attributed to a higher chain organization of PCL with higher loading of Mg particles, whereby chain organization is highly influenced by the amount of the crystalline phase as reported by Elzein at.al [40]. Moreover, since the plain PCL and composite assembled 3D scaffolds were thermally treated at $55{ }^{\circ} \mathrm{C}$, the PCL scaffold undergoes recrystallization after incorporation of $\mathrm{Mg}$ particles. Hence, this explains why the crystallinity is altered after incorporation of $\mathrm{Mg}$ particles.

\subsection{X-ray diffraction (XRD) analysis}

XRD spectra of plain PCL before and after thermal treatment, and the PCL/Mg composites (5 and 8 wt. \%) are shown in Figure 6a. PCL produced two peaks at approximately 23.8 and $21.38^{\circ}$ as reported previously [37]. The two composites produced an extra peak, at $37^{\circ}$ (Fig. 6a). This peak was also found in the spectrum of pure Mg (Fig. 1) and is caused by the combination of Mg with PCL in the 3D fibrous scaffold. The intensity of this peak depends on the Mg-particles loaded in the PCL scaffold. Furthermore, the intensity of PCL peaks in the PCL/Mg (5 and 8 wt. \%) spectrum (Fig. 6a) was higher than that in pure PCL. This could be caused by the change in coordinate property of the molecules of PCL, or due to interfacial hydrogen bonding taking place between the Mg-particles and PCL molecules during the thermal treatment [41]. This will be explained in the FITR analysis.

\subsection{FTIR analysis}

This behavior of crystallinity changes at the macromolecular level was further investigated using FTIR analysis (Fig. 6b). Characteristic peaks at 3300-3700, 1725, 852-1480 and $720 \mathrm{~cm}^{-1}$ were observed in PCL polymers $[40,42]$ (Fig. 6b). The FTIR spectra of PCL/Mg- 
particles (5 and 8 wt. \%) (Fig. 6b) show that the peaks between 3200 and $3700 \mathrm{~cm}^{-1}$ were much more intense in the presence of Mg-particles within the PCL matrix. Thus, these changes suggest that $\mathrm{Mg}$ particles were indeed bonded to PCL after heat treatment and this might enhance the interaction and the interfacial strength between the particle and polymer molecules. It has been reported that electrostatic forces develop at the interface between materials that have different electronic band structures $[43,44]$. Thus, the interfacial bonding is strong in the case of the higher percentage of $\mathrm{Mg}$ particles loaded into the PCL. To evaluate the extensive intermolecular hydrogen bonding tendency of the PCL matrix, the absorption peaks of the carbonyl groups are the prime consideration [37, 45]. Accordingly, a considerable shift of the hydrogen bonded absorption peak towards the higher carbonyl in the case of the 5 and 8 wt. \% Mg particle loaded samples was shown compared to the pure PCL samples (Fig. 6b). This indicates that the majority of carbonyl groups in caprolactone linkages participated in hydrogen bonding with the oxide/hydroxide (-O/-OH) groups present on the Mg particle surface $[41,46]$, which is likely to have occurred during the fabrication process (Fig. 1). In addition, the peak intensity ratio gives an estimation of the degree of intermolecular interaction. This can be explained by the large number of free ends on the PCL polymer chain, which provide abundant numbers of free carboxyl groups for electrostatic intermolecular interaction between PCL molecules encapsulating Mg particles [41]. This electrostatic intermolecular interaction changes the decomposition temperature and crystalline structure of the composite scaffolds (Figs. 5 and 6 and Table. 1), possibly because of the reorganization of polymer chain structure due to incorporation of Mg particles.

It has been reported that when the crystallinity of the polymer is increased, the degree of phase separation and structure organization also increase accordingly [32]. Hence, this change may reinforce the interfacial adhesion properties of PCL matrix and Mg particles. This interfacial strength possibly occurs during the airbrushing spinning process due to the 
difference in kinetic energy between the $\mathrm{Mg}$ particles (higher kinetic energy due to higher mass) and PCL molecules/fibers (lower kinetic energy due to lower mass), as described in detail in our previous studies [20,22]. Magnesium particles ejected from the airbrush gun collide with the PCL fibers at high speeds, which likely causes mobility changes and chain reorganization of the PCL, subsequently resulting in a higher binding strength between these two components. Hence, from the results of the DSC, XRD and FTIR analysis, the increased crystallinity can be attributed to the incorporation of $\mathrm{Mg}$ particles to the PCL matrix. As such, Mg particles loaded into the PCL matrix along with the thermal treatment process would provide adequate energy for PCL molecules to overcome their energy threshold such that the PCL molecule could migrate to their crystalline position, as revealed by DSC and FTIR. However, the mechanism of chemical bonding interactions between the PCL molecules and $\mathrm{Mg}$ particles are not fully clear, therefore, it is necessary to investigate further the interfacial properties of these scaffolds in future research. Together these findings suggest that the addition of magnesium particles to the PCL matrix would enhance the mechanical properties compared with plain PCL scaffolds, similar to observations by Wong et al and others [28, 29].

\subsection{Mechanical properties and in vitro characterization}

The stress-strain behavior of the assembled 3D scaffolds containing plain PCL, 5 and 8 wt. \% of Mg particles following hydrothermal treatment was assessed (Fig. 7a). The stressstrain curves show a plateau of roughly constant stress leading into a final region of steeply increasing stress. The curves illustrate that the behavior of the scaffold was modified after the incorporation of $\mathrm{Mg}$ particles. Increasing the $\mathrm{Mg}$ particle content of the 3D scaffold enhanced the mechanical properties, as demonstrated by higher compressive strength and young's modulus. The scaffolds containing 8 wt. \% Mg-particles showed increased compression strength and compressive modulus of $78 \pm 17.5$ at and $2.42 \pm 0.23 \mathrm{MPa}$, compared to plain PCL which was $42 \pm 12$ and $0.53 \pm 0.15 \mathrm{MPa}$, respectively. The presence of $\mathrm{Mg}$ particles increased 
the strength, compressive modulus and the ability to resist deformation, which is consistent with the findings of Wong et.al who showed that the incorporation of Mg particles in PCL matrix can enhance the mechanical properties [28]. Figure $7 \mathrm{~b}$ shows that both plain PCL and PCL/Mg scaffolds experienced barreling. The micrograph shown in Fig. 7c is taken at low magnification in order to show the Mg particles within the matrix after mechanical testing. The tests revealed a threshold of strength resisting deformation, however, $\mathrm{Mg}$ particles increased the strength of the composite.

Figure $7(\mathrm{~d}$ and e) shows the results obtained from compression testing of the scaffolds after immersion in PBS solution up to 60 days. Both elasticity and strength progressively decreased. A reduction in the compression properties of plain PCL scaffold with time of degradation was not significantly $(\mathrm{p}<0.05)$ changed whereas the $3 \mathrm{D}$ scaffolds containing $\mathrm{Mg}$ particles showed noteworthy gradual reduction with immersion time. After 60 days, the modulus and the compressive strength are reduced by more than $55 \%$ compared with the original material. The positive effect of $\mathrm{Mg}$ particles on the mechanical properties before degradation was due to the reinforcement effect of the filler, as well as an enhanced fillerpolymer interaction. The assembled 3D fibrous scaffolds were stable with immersion for up to two months and did not tear or come apart during the mechanical testing.

Figure 8a shows the concentration of magnesium ions released from the PCL/Mg composite 3D fibrous scaffolds over the two months of immersion in PBS. The magnesium ion release profiles leached from the 5 and $8 \mathrm{wt} \%$ composites were similar, with $\mathrm{Mg}$ concentration increasing steadily for both scaffolds, from $55 \mathrm{ppm}$ and $70 \mathrm{ppm}$ after 3 days of immersion to $220 \mathrm{ppm}$ and $270 \mathrm{ppm}$ after 2 months of immersion, respectively. The $\mathrm{pH}$ of plain PCL, 5, and 8 wt. \% Mg particle 3D scaffolds after 2 months of immersion are shown in Figure 8b. The pH value increases associated with increasing $\mathrm{Mg}$ amounts in the scaffolds can be ascribed to more $\mathrm{OH}^{-}$release into PBS solution by degradation of $\mathrm{Mg}$ [29][32]. The existence of chloride $\left(\mathrm{Cl}^{-}\right)$ 
ions in PBS transforms $\mathrm{Mg}$ hydroxide into soluble $\mathrm{MgCl}_{2}$; resulting in excess $\mathrm{OH}^{-}$ions that eventually raise the $\mathrm{pH}$. Upon degradation, the $\mathrm{pH}$ values increased from 7.37 to 7.85 and 8.1 for 5 and 8 wt. \% Mg particles loaded composites, respectively. However, the $\mathrm{pH}$ value of pure PCL is found to drop below 7.2 at the 2-month time point, which is similar to previous reports [28]. The $\mathrm{pH}$ behavior of the buffered solution containing polymer/Mg composites is consistent with the literature $[29,32,47]$ and addresses an important issue regarding the applicability of $\mathrm{Mg}$ in the biomedical field i.e. the possible alkalization of the physiological environment. As aqueous liquid diffuses within the fibrous matrix, it reaches the surface of $\mathrm{Mg}$ particles leading to the corrosion of the metal, which was manifested in 2.6 and $3.45 \mathrm{mg}$ weight loss (Fig. S3) after 2 months of immersion for the 5 and $8 \% \mathrm{Mg}$ composites respectively. The weight loss of the degraded composites shows that particles that are encapsulated by a thin polymer film react with the surrounding media at the early time point. The polymeric matrix is playing an important role in controlling the high corrosion rate of $\mathrm{Mg}$ particles and may hinder higher alkalization of the media [28, 29]. This indicates that, although degradation in these polymers occurs through surface erosion [48], the bulk degradation of the $\mathrm{Mg}$ particles does not occur and their release is controlled by the diffusion rate of PBS within the polymeric matrix. Effectively, the solution needs time to diffuse among the polymer chains and reach the capsulated $\mathrm{Mg}$ particles inside the scaffold, with consequently sustained release of $\mathrm{Mg}$ particles over time.

The SEM morphology of the plain and composite scaffolds after 2 months of PBS immersion is shown in Fig. 8c. Tiny cracks and a rough surface morphology were observed on the PCL fibers of all scaffolds after immersion for two months. These cracks expose new polymer surface area to the PBS, which by degrading releases polymer molecules into the media. Another possible concern regarding the application of polymer based composites refers to the acidification of the media once the $\mathrm{Mg}$ particles have been completely released, due to 
the remaining polymer in the scaffold. In the authors' opinion, this would not represent a critical problem due to the low degradation and absorption rate of PCL [26]. PCL is degraded much slower than other known members of the aliphatic polyester family, such as polylactide (PLA), which causes acidification problems during the PLA degradation process $[29,49]$. The degradation mechanism of PCL and PLA however is similar which is attributed to random hydrolytic ester cleavage and weight loss through the diffusion of oligometric species from the bulk. It has been found that the degradation of PCL with high molecular weight $(\mathrm{Mw}>50,000)$ and high crystallinity is remarkably slow, requiring three years for complete removal from the body [50]. Hence, the degradation rate is reduced when the crystallinity increased. Due to the increased crystallinity after incorporation of $\mathrm{Mg}$ particles (Table. 1), the degradation rate would therefore be reduced. Taken together, it is expected that the complete release of $\mathrm{Mg}$ particles from the PCL matrix following implantation will not have any effect on PCL degradation.

\subsection{Osteoblasts-like cells response to assembled $3 D$ fibrous scaffold}

Cell attachment, spreading and infiltration/migration occur during the crucial early stages of cell-material interactions. In the present study, the limitations of small pore size and layer thickness of 2D fibrous scaffold could be overcome through the use of a $3 \mathrm{D}$ cellular scaffold. The nanofibers provide a scaffold for cell spreading and the large pore sizes benefit cell migration throughout the scaffold. To validate the assembled 3D fibrous constructs as tissue engineering scaffolds, their ability to support attachment, spreading and infiltration of human osteoblasts was assessed. The 3D fibrous scaffolds fabricated from PCL and PCL/Mg composites were seeded with human osteoblasts-like cells. Both plain and composite 3D fibrous scaffolds elicited favorable osteoblast penetration with fluorescence staining after 1 day of cell culture showing evenly distributed cells on both plain PCL and composite scaffolds, (Fig. 9a and c). High magnification single cell images (Fig. 9b and d) show the cells morphology on both surfaces. On the 3D composite scaffolds loaded with $\mathrm{Mg}$ particles, the 
osteoblasts attained a more elongated morphology with numerous filopodia (Fig. 9d) than that observed with the cells cultured on plain PCL (Fig. 9b), which was similar to previous observations of osteoblasts on composite scaffolds incorporating Mg [51]. The cells seeded on the composite scaffold were confluent, stretching across the substrate by day 7 of culture (Fig. 10a and $b$ and Fig. S4 of supporting information).

The cellular infiltration depth was determined as the distance from the surface of the scaffold to the innermost observed cells. It is expected that the interconnected scaffold pores provide a large volume of space for cells to proliferate and infiltrate and allow nutrient transfer within the structure of the scaffold. While cells could attach and proliferate on both scaffolds, a distinct difference between the infiltrations of cells onto the assembled fibrous scaffolds was detected via confocal laser microscopy (Fig. 10b-f). Although the mean depth of cell penetration was greater in the plain PCL 3D network structure $(175 \pm 45 \mu \mathrm{m})$ than in the composite scaffold $(125 \pm 36 \mu \mathrm{m})$, the area covered by cells $(\sim 97 \%$ of total surface area) and the cell volume $(\sim 85 \%)$ on 3D PCL/Mg composite scaffolds was higher than on pristine PCL (surface area, $\sim 72 \%$ and volume, $\sim 78 \%$, Fig. 10). With longer culture time, at 14 days cells are continuing to spread, grow and migrate through the entire structure of the assembled 3D composite scaffold (Fig. S5 and video VS2 of supplementary materials) more than through the plain PCL scaffold.. Interestingly, interconnected sheet-like cells $210 \pm 30 \mu \mathrm{m}$ in depth was observed through the assembled 3D composite scaffold (Fig. S5). It seems that with longer culture time (14 days), unencapsulated $\mathrm{Mg}$ particles were degraded and released from the 3D composite scaffold allowing more space for cell migration through the assembled composite scaffold. These results suggest that the differences in the structure and composition of plain PCL and PCL/Mg 3D fibrous scaffolds might have an effect on osteoblast morphology, but both types of assembled 3D fibrous scaffolds allowed osteoblasts to penetrate inside the scaffolds. The role of cell shape in directing cell function has been illustrated by other 
researchers [52] and the effects of scaffold architecture on cell shape and function have also been discussed elsewhere $[50,53]$.

Data presented in this study indicates that a more porous, assembled airbrushed fibers with cellular structure allows for thorough cell penetration and migration. The ability of cells to penetrate within the scaffolds supports the possibility of creating/multilayered interconnected cellular constructs (as s in Fig. S5). 3D matrices have the potential to extend cellular interactions into a third $\mathrm{z}$-direction with greater lateral and vertical cell-cell connectivity within the entire open network of the scaffolds that may also control cellular fate $[28,44,51]$.

In order to verify the results of confocal imaging, the cell density and viability up to 14 days culture on the assembled fibrous scaffolds were investigated via DNA quantification (Picogreen assay) and metabolic activity (Alamrblue assay) respectively (Fig. 11). As expected, the assembled composite fibrous scaffold was capable of facilitating cell proliferation as shown using alveolar-bone derived human osteoblast cells. At 1 and 4 days culture, the results showed that both tissue culture plastic (TCP) and the composite scaffold had a higher cell density than plain PCL scaffold. DNA quantification (picogreen assay) indicated that the cell density increased with length of cell culture time and significantly increased after 7 and 14 days in culture in assembled composite scaffolds (Fig. 11a). In addition, the viability (Alamrblue) results are consistent with the cells density. It can be seen from Fig. $11 \mathrm{~b}$ that the $\%$ viability of cells is significantly higher at 7 and 14 days of culture for the composite scaffold compared to the TCP and plain PCL scaffold. Previous studies have confirmed the ability of airbrushing produced 2D nanofiber scaffolds to support tissue engineering applications [20,23], and the current work demonstrates that airbrushed assembled 3D nanofiber scaffolds may also have tissue engineering potential. If this is taken as the starting point, comparison of the relative increase in DNA quantification and metabolic activity for 
composite 3D scaffolds is interesting. It can be seen that cell growth on the PCL/Mg 3D scaffold, relative to the TCP control and plain PCL, had increased more rapidly at the longer culture time point (Fig. 11). This may be due to the ions released from $\mathrm{Mg}$ particles stimulating osteoblast cell responses [30]. Wong et al [28, 51] examined a scaffold with the same composition and in terms of cell proliferation and viability, the scaffold loaded with $\mathrm{Mg}$ particles significantly stimulated osteoblasts compared with a pure PCL scaffold. In addition, this preliminary in vitro results were consistent were previous studies, including ours, which showed that released $\mathrm{Mg}$ ions were able to stimulate cellular metabolic activity, bone growth and bone healing $[28,30,54-58]$. This again supports the concept that the organic fiber/metallic absorbable particle system can facilitate cell attachment, proliferation and formation of appropriate interconnective tissue. The exact mechanism, however, of magnesium's impact on cell behavior in the present assembled 3D fibrous scaffolds is not fully understood, but it appears that the magnesium particles in the composite assembled fibrous scaffolds support a higher spread area and total volume of osteoblasts in vitro. This may warrant further investigation.

The results of the in vitro tests suggest that improved osteoblast attachment/ proliferation and migration may be attributed to the physical structure of the assembled 3D fibrous morphology scaffold and the beneficial release of $\mathrm{Mg}$ ions from the hybrid composites, confirming that short fibers assembled into a 3D interconnected architecture incorporating biodegradable metallic particles, such as $\mathrm{Mg}$, may be suitable for tissue engineering applications.

\section{Conclusion}

An assembled 3D interconnected porous network structure of plain and composite short nanofibers were successfully fabricated by combining airbrushing, as a cost-effective and simple spinning approach, with thermal cross-linking of the molded short fibers for the first 
time. Together, our findings demonstrate a proof of concept for the design of a new 3D scaffold with an open interconnected porous architecture and controlled thickness up to $10 \mathrm{~mm}$. Airbrushing can produce short nanofibers under controlled conditions and the polymer solution used during the spraying process can encapsulate $\mathrm{Mg}$ particles to help control the release of $\mathrm{Mg}$ ions in a sustained manner into the aqueous media for up to two months. The 3D fibrous scaffolds encouraged human osteoblasts to attach, spread and migrate throughout the porous scaffolds. More specifically, the 3D composite scaffolds containing Mg particles induced higher mechanical properties, superior cell attachment and proliferation and metabolic activity and created a cell sheet-like through the entire 3D porous structure with longer culture times compared to the assembled plain PCL scaffold. Thus, the design and assembly of short nanofibers into interconnected porous 3D structures using this manufacturing technique could have significant potential in improving the bio-integration of ECM-mimicking 3D tissue engineered scaffolds.

\section{Conflict of interests}

The authors declare no conflicts of interest of this work.

\section{Appendix A. Supplementary data}

Supplementary data related to this article can be found at 


\section{References}

[1] S. Bose, S. Vahabzadeh, A. Bandyopadhyay, Materials Today 16 (2013) 496-504.

[2] Y. Si, J. Yu, X. Tang, J. Ge, B. Ding, Nature communications 5 (2014) 5802.

[3] A. Abdal-hay, A. Memic, K.H. Hussein, Y.S. Oh, M. Fouad, F.F. Al-Jassir, H.-M. Woo, Y. Morsi, X. Mo, S. Ivanovski, European Polymer Journal 96 (2017) 27-43.

[4] S. Juqing, Z. Guanglin, W. Lin, A. Geng, S. Xuetao, W. Yingjun, Biofabrication 9 (2017) 015018.

[5] T.C. Lim, K.S. Chian, K.F. Leong, Journal of Biomedical Materials Research Part A 94 (2010) 1303 1311.

[6] J.M. Ugartemendia, A. Larrañaga, H. Amestoy, A. Etxeberria, J.R. Sarasua, European Polymer Journal 98 (2018) 411-419.

[7] A. Tilman, D. Falko, K. David, V. Corina, K. Paula, L. Günter, L. Anja, G. Michael, Biofabrication 10 (2018) 045002.

[8] B. Sun, Y.Z. Long, H.D. Zhang, M.M. Li, J.L. Duvail, X.Y. Jiang, H.L. Yin, Progress in Polymer Science 39 (2014) 862-890.

[9] Y. Yang, S. Basu, D.L. Tomasko, L.J. Lee, S.-T. Yang, Biomaterials 26 (2005) 2585-2594.

[10] M. Ribeiro, M.A. de Moraes, M.M. Beppu, M.P. Garcia, M.H. Fernandes, F.J. Monteiro, M.P. Ferraz, European Polymer Journal 67 (2015) 66-77.

[11] F. Riccitiello, A. De Luise, R. Conte, S. D'Aniello, V. Vittoria, A.Di Salle, A. Calarco, G. Peluso, European Polymer Journal 99 (2018) 289-297.

[12] F.S. Senatov, M.Y. Zadorozhnyy, K.V. Niaza, V.V. Medvedev, S.D. Kaloshkin, N.Y. Anisimova, M.V. Kiselevskiy, K.-C. Yang, European Polymer Journal 93 (2017) 222-231.

[13] P. Bhattacharjee, D. Naskar, H.-W. Kim, T.K. Maiti, D. Bhattacharya, S.C. Kundu, European Polymer Journal 71 (2015) 490-509.

[14] G. Johan, M. Kajsa, M. Andreas, H. Karl, G. Paul, E. Fredrik, Biofabrication 10 (2018) 034105.

[15] W. Chen, J. Ma, L. Zhu, Y. Morsi, H. Ei-Hamshary, S.S. Al-Deyab, X. Mo, Colloids and Surfaces B: Biointerfaces 142 (2016) 165-172.

[16] B.K. Gu, S.J. Park, M.S. Kim, C.M. Kang, J.-I. Kim, C.-H. Kim, Carbohydrate Polymers 97 (2013) 6573.

[17] A. Abdal-hay, N.A.M. Barakat, J.K. Lim, Sci. Adv. Mater 4 (2012) 1-8.

[18] A. Abdal-hay, A.S. Hamdy, M.Y. Abdellah, J. Lim, Materials Letters 126 (2014) 267-270.

[19] A. Abdal-hay, Y.S. Oh, A. Yousef, H.R. Pant, P. Vanegas, J.K. Lim, Applied Surface Science 307

(2014) 69-76.

[20] A. Abdal-hay, F.A. Sheikh, J.K. Lim, Colloids Surf B Biointerfaces 102 (2013) 635-643.

[21] W. Tutak, S. Sarkar, S. Lin-Gibson, T.M. Farooque, G. Jyotsnendu, D. Wang, J. Kohn, D. Bolikal,

C.G. Simon, Jr., Biomaterials 34 (2013) 2389-2398.

[22] A. Abdal-hay, A.S. Makhlouf, K.A. Khalil, ACS Appl Mater Interfaces 7 (2015) 13329-13341.

[23] K. Hoffman, D. Skrtic, J. Sun, W. Tutak, Tissue Engineering Part C: Methods 21 (2014) 284-291.

[24] A. Abdal-Hay, A.S. Hamdy, K.A. Khalil, J.H. Lim, Mater Sci Eng C Mater Biol Appl 49 (2015) 681690.

[25] Y. Chen, Y. Song, S. Zhang, J. Li, C. Zhao, X. Zhang, Biomedical Materials 6 (2011) 025005.

[26] M.A. Woodruff, D.W. Hutmacher, Progress in Polymer Science 35 (2010) 1217-1256.

[27] B. Imre, H. Gojzewski, C. Check, R. Chartoff, G.J. Vancso, Macromolecular Chemistry and Physics 219 (2018) 1700214-n/a.

[28] H.M. Wong, S. Wu, P.K. Chu, S.H. Cheng, K.D.K. Luk, K.M.C. Cheung, K.W.K. Yeung, Biomaterials 34 (2013) 7016-7032.

[29] S.C. Cifuentes, R. Gavilán, M. Lieblich, R. Benavente, J.L. González-Carrasco, Acta Biomaterialia 32 (2016) 348-357.

[30] Y. Zhang, J. Xu, Y.C. Ruan, M.K. Yu, M. O'Laughlin, H. Wise, D. Chen, L. Tian, D. Shi, J. Wang, Nature medicine 22 (2016) 1160. 
[31] J.B. Lee, S.I. Jeong, M.S. Bae, D.H. Yang, D.N. Heo, C.H. Kim, E. Alsberg, I.K. Kwon, Tissue Eng Part A 17 (2011) 2695-2702.

[32] H.M. Wong, K.W. Yeung, K.O. Lam, V. Tam, P.K. Chu, K.D. Luk, K.M. Cheung, Biomaterials 31 (2010) 2084-2096.

[33] J. Fernández, A. Larrañaga, A. Etxeberría, J.R. Sarasua, Polymer Degradation and Stability 98 (2013) 481-489.

[34] J. Fernández, A. Etxeberría, J.R. Sarasua, Polymer Degradation and Stability 98 (2013) 12931299.

[35] H. Dan, C. Vaquette, A.G. Fisher, S.M. Hamlet, Y. Xiao, D.W. Hutmacher, S. Ivanovski,

Biomaterials 35 (2014) 113-122.

[36] H. Haase, S. Ivanovski, M. Waters, P. Bartold, Journal of periodontal research 38 (2003) 366-374.

[37] A. Abdal-hay, M. Bartnikowski, S. Hamlet, S. Ivanovski, Materials Science and Engineering: C 82

(2018) 10-18.

[38] S.J. Lee, S.H. Oh, J. Liu, S. Soker, A. Atala, J.J. Yoo, Biomaterials 29 (2008) 1422-1430.

[39] M. Holland, Physical Review 132 (1963) 2461.

[40] T. Elzein, M. Nasser-Eddine, C. Delaite, S. Bistac, P. Dumas, Journal of Colloid and Interface Science 273 (2004) 381-387.

[41] L. Xu, A. Yamamoto, Colloids Surf B Biointerfaces 93 (2012) 67-74.

[42] C.-S. Wu, Polymer 46 (2005) 147-155.

[43] M. Catauro, F. Bollino, F. Papale, R. Giovanardi, P. Veronesi, Mater Sci Eng C Mater Biol Appl 43 (2014) 375-382.

[44] M. Sung Woon, K. Yeong Mu, K. Byung Hoon, Japanese Journal of Applied Physics 53 (2014) 11 RB01.

[45] A.K. Barick, D.K. Tripathy, Composites Part A: Applied Science and Manufacturing 41 (2010) 1471-1482.

[46] H. Deka, N. Karak, Nanoscale research letters 4 (2009) 758.

[47] F. Witte, F. Feyerabend, P. Maier, J. Fischer, M. Stormer, C. Blawert, W. Dietzel, N. Hort, Biomaterials 28 (2007) 2163-2174.

[48] F.v. Burkersroda, L. Schedl, A. Göpferich, Biomaterials 23 (2002) 4221-4231.

[49] K. Rezwan, Q.Z. Chen, J.J. Blaker, A.R. Boccaccini, Biomaterials 27 (2006) 3413-3431.

[50] S. Wu, X. Liu, K.W.K. Yeung, C. Liu, X. Yang, Materials Science and Engineering: R: Reports 80 (2014) 1-36.

[51] H.M. Wong, P.K. Chu, F.K.L. Leung, K.M.C. Cheung, K.D.K. Luk, K.W.K. Yeung, Progress in Natural Science: Materials International 24 (2014) 561-567.

[52] J. Folkman, A. Moscona, Nature 273 (1978) 345-349.

[53] G. Kumar, C.K. Tison, K. Chatterjee, P.S. Pine, J.H. McDaniel, M.L. Salit, M.F. Young, C.G. Simon, Biomaterials 32 (2011) 9188-9196.

[54] T. Kokubo, Journal of Non-Crystalline Solids 120 (1990) 138-151.

[55] H. Zreiqat, C.R. Howlett, A. Zannettino, P. Evans, G. Schulze-Tanzil, C. Knabe, M. Shakibaei, Journal of Biomedical Materials Research 62 (2002) 175-184.

[56] E. Boanini, M. Gazzano, A. Bigi, Acta biomaterialia 6 (2010) 1882-1894.

[57] A. Abdal-hay, M. Dewidar, J.K. Lim, Applied Surface Science 261 (2012) 536-546.

[58] A. Abdal-hay, N.A.M. Barakát, J.K. Lim, Colloids and Surfaces A: Physicochemical and Engineering Aspects 420 (2013) 37-45. 


\section{Graphical Abstract}

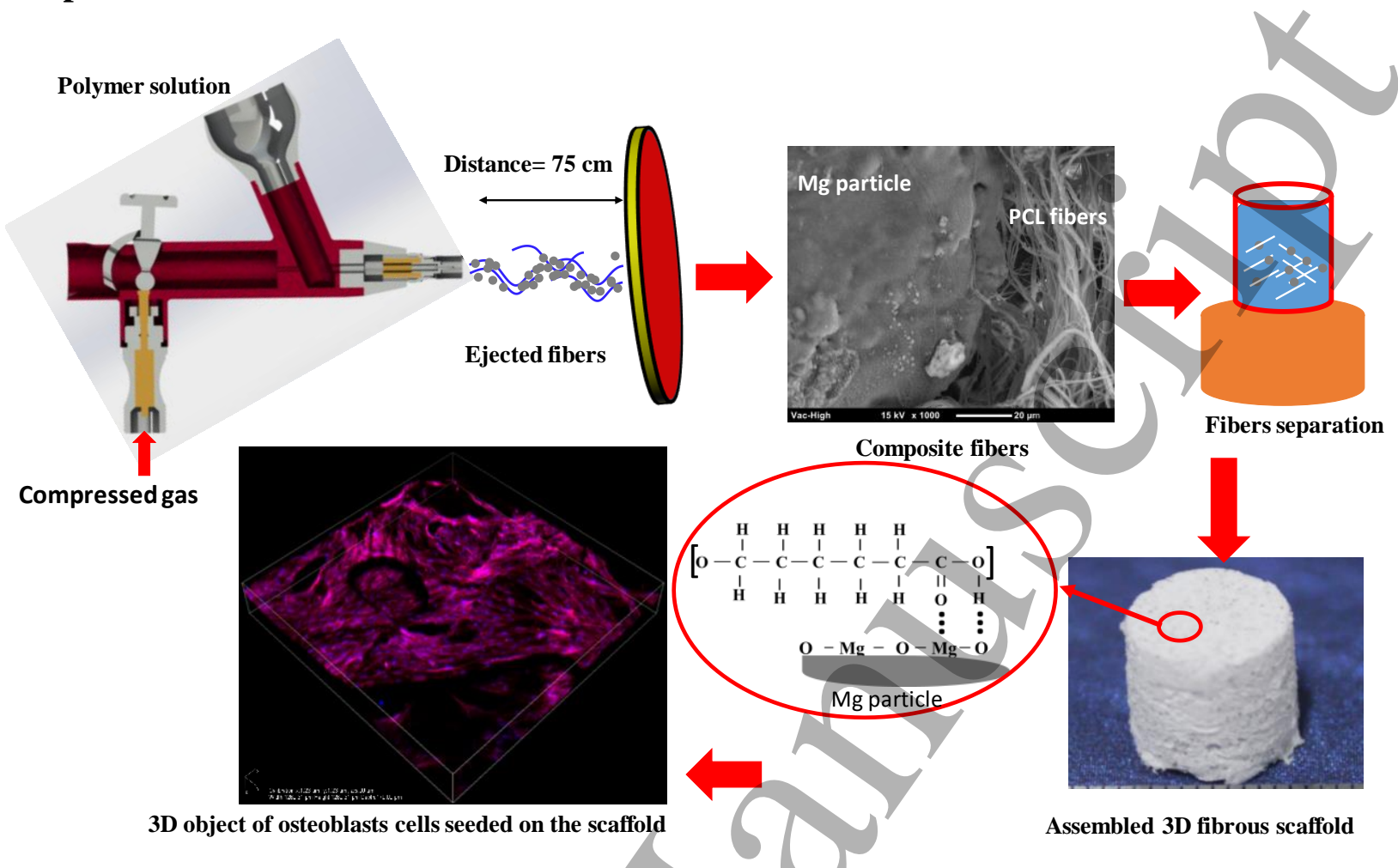




\section{Figures and Tables}

Table 1. Thermal properties of different PCL assembled 3D fibrous scaffold determined by differential scanning calorimetry

\begin{tabular}{lllll}
\hline Scaffold & $\mathbf{T}_{\mathbf{m}}\left({ }^{\circ} \mathbf{C}\right)$ & $\boldsymbol{\Delta} \boldsymbol{H}_{\mathbf{m}}\left[\mathbf{J ~ g} \mathbf{~}^{-1}\right]$ & $\mathbf{T}_{\mathbf{c}}\left({ }^{\circ} \mathbf{C}\right)$ & $\boldsymbol{X c}[\boldsymbol{\%}]$ \\
\hline Plain PCL & 56.99 & 65.05 & 28.85 & 47.83 \\
5 wt.\% Mg & 57.28 & 72.43 & 29.98 & 53.26 \\
8 wt.\% Mg & 57.18 & 79.78 & 32.38 & 58.67 \\
& & & &
\end{tabular}

$\mathrm{T}_{\mathrm{m}}$ represents the melting temperature; $\mathrm{T}_{\mathrm{c}}$ represents the crystallization temperature; $\Delta \mathrm{H}_{\mathrm{m}}$ represents the change of melting of heat and $\mathrm{Xc}$ represents the crystallinity. The melting temperature $\left(\mathrm{T}_{\mathrm{m}}\right)$ and the change of melting of heat $\left(\Delta \mathrm{H}_{\mathrm{m}}\right)$ were obtained from the heating thermograms while the crystallization temperature $\left(T_{c}\right)$ was identified from the cooling thermograms. 


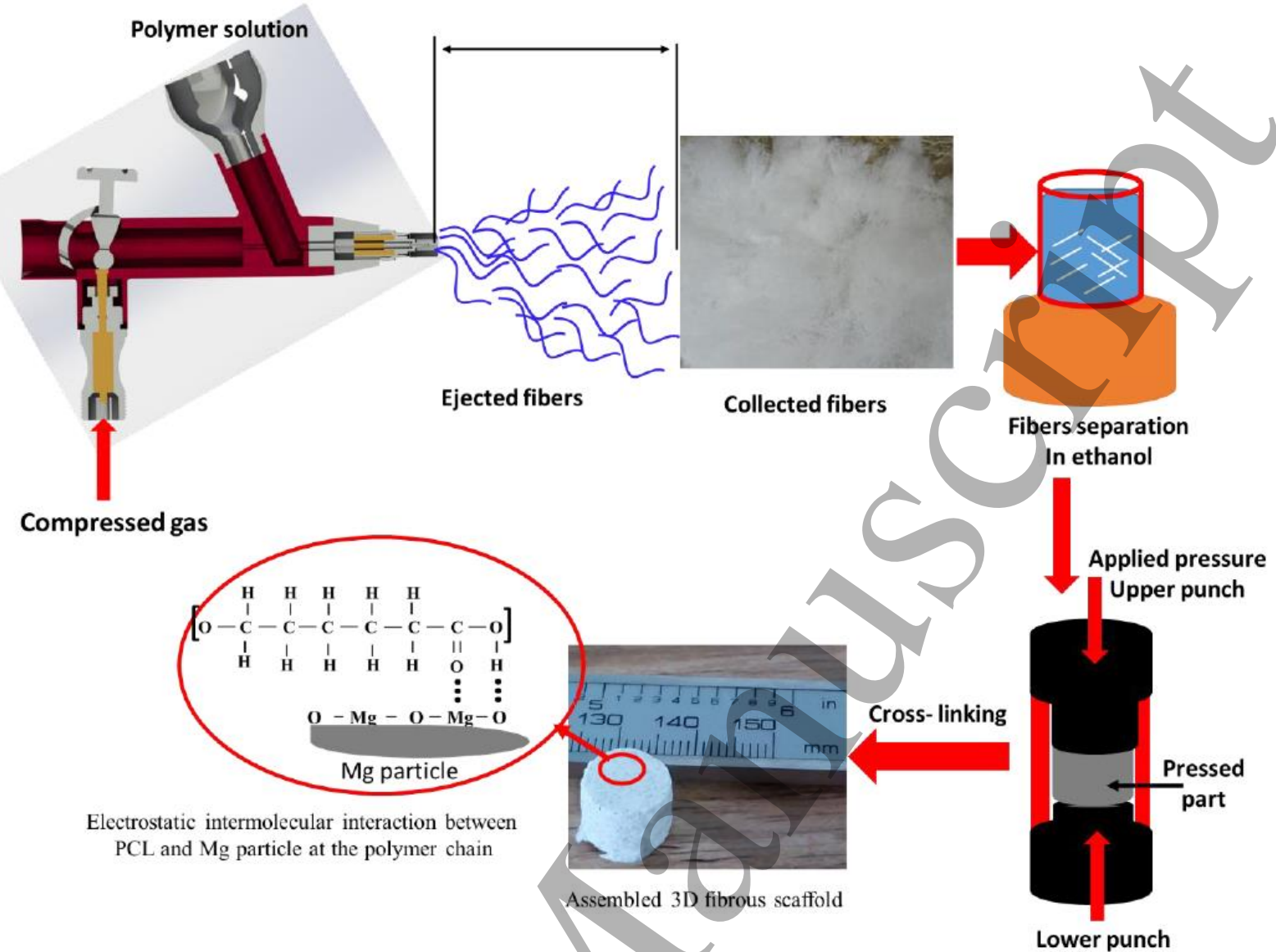

Figure 1. Fabrication process of assembled airbrushed nanofibers into a 3D interconnected porous architecture using mold pressing at room temperature and subsequent $55^{\circ} \mathrm{C}$ thermal treatment to provide cross-linkage between the fibers. 


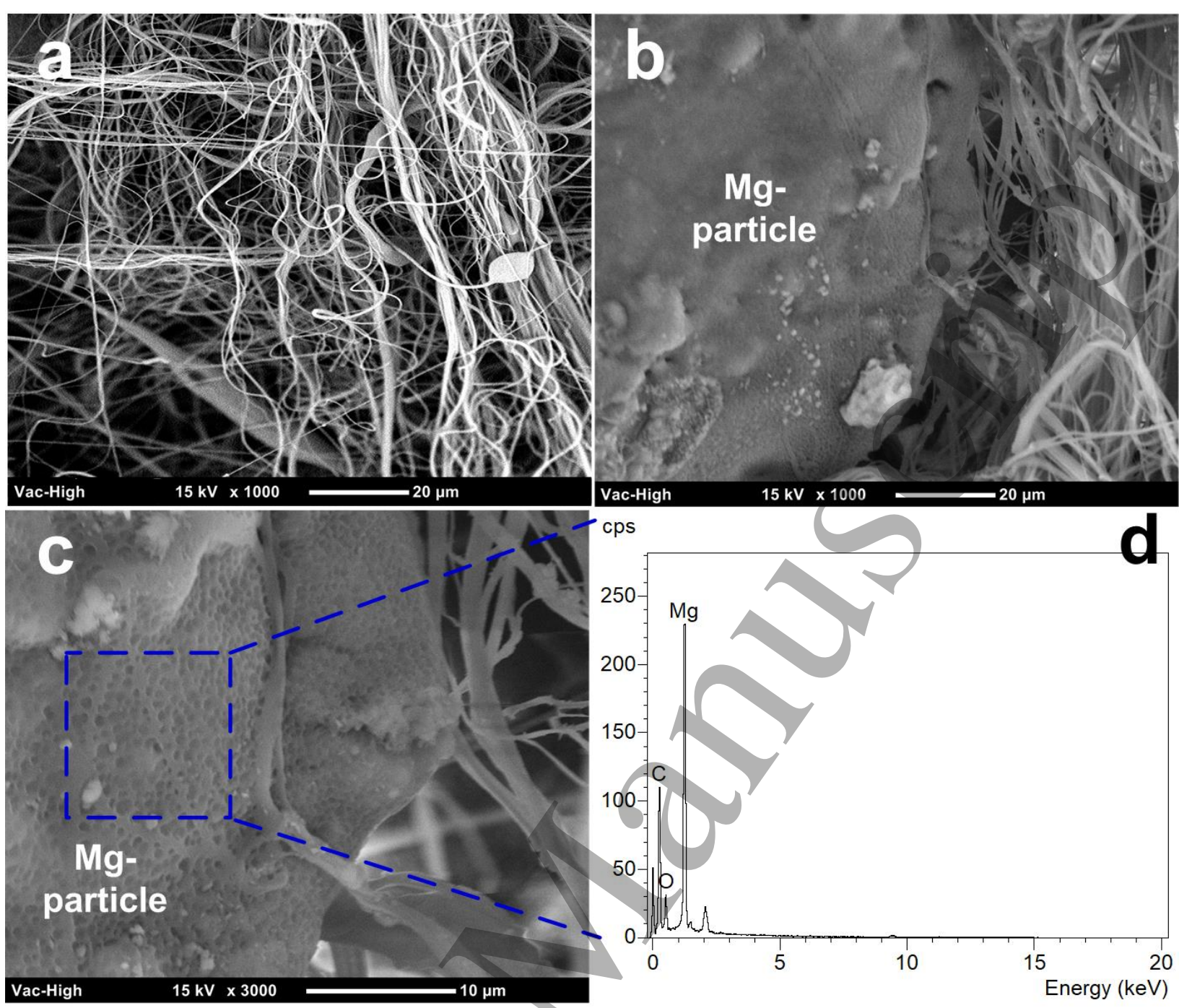

Figure 2. SEM micrographs of (a) plain PCL, (b) PCL/Mg composite fibers (low magnification) and (c) PCL/Mg composite fibers (high magnification). The dashed blue box in (c) shows the formation of a PCL porous film on the surface of Mg particles during the airbrushing fabrication process. (d) Energy-dispersive X-ray spectroscopy of selected area (dashed blue box inset) of (c). 

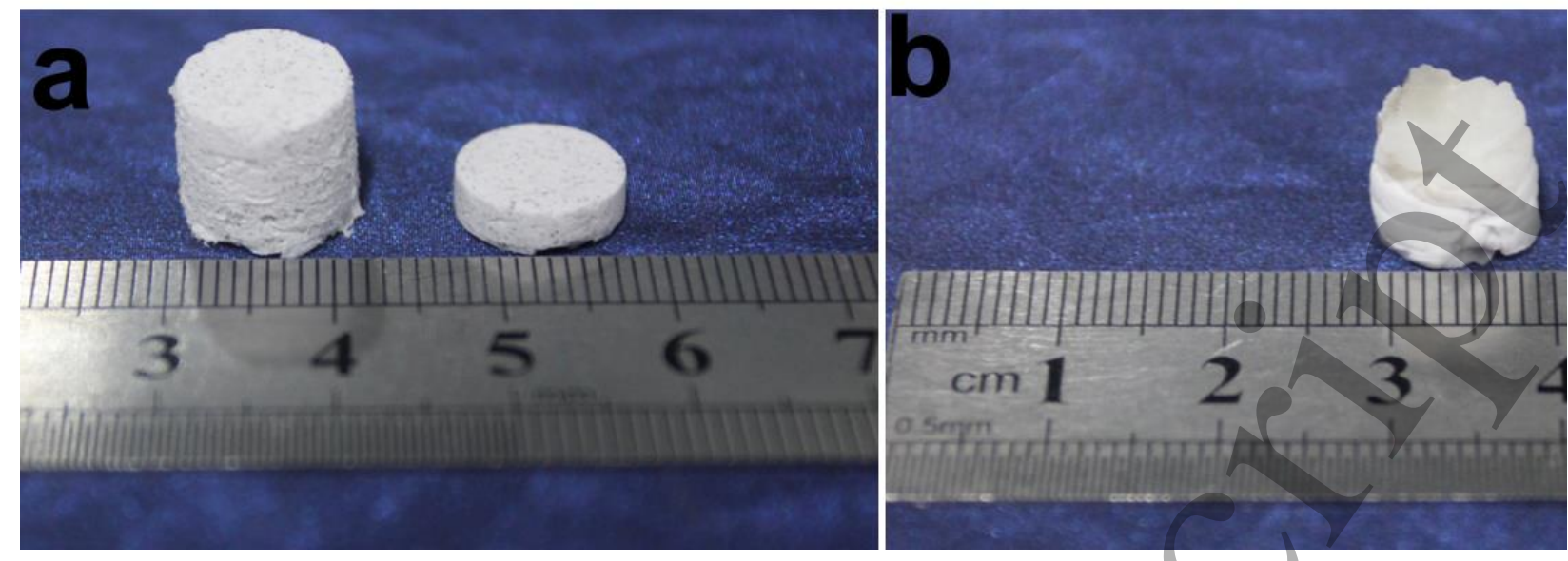

Figure 3. Assembled 3D fibrous scaffolds cross-linked at (a) $55^{\circ} \mathrm{C}$ and (b) $60{ }^{\circ} \mathrm{C}$ for $15 \mathrm{~min}$. 


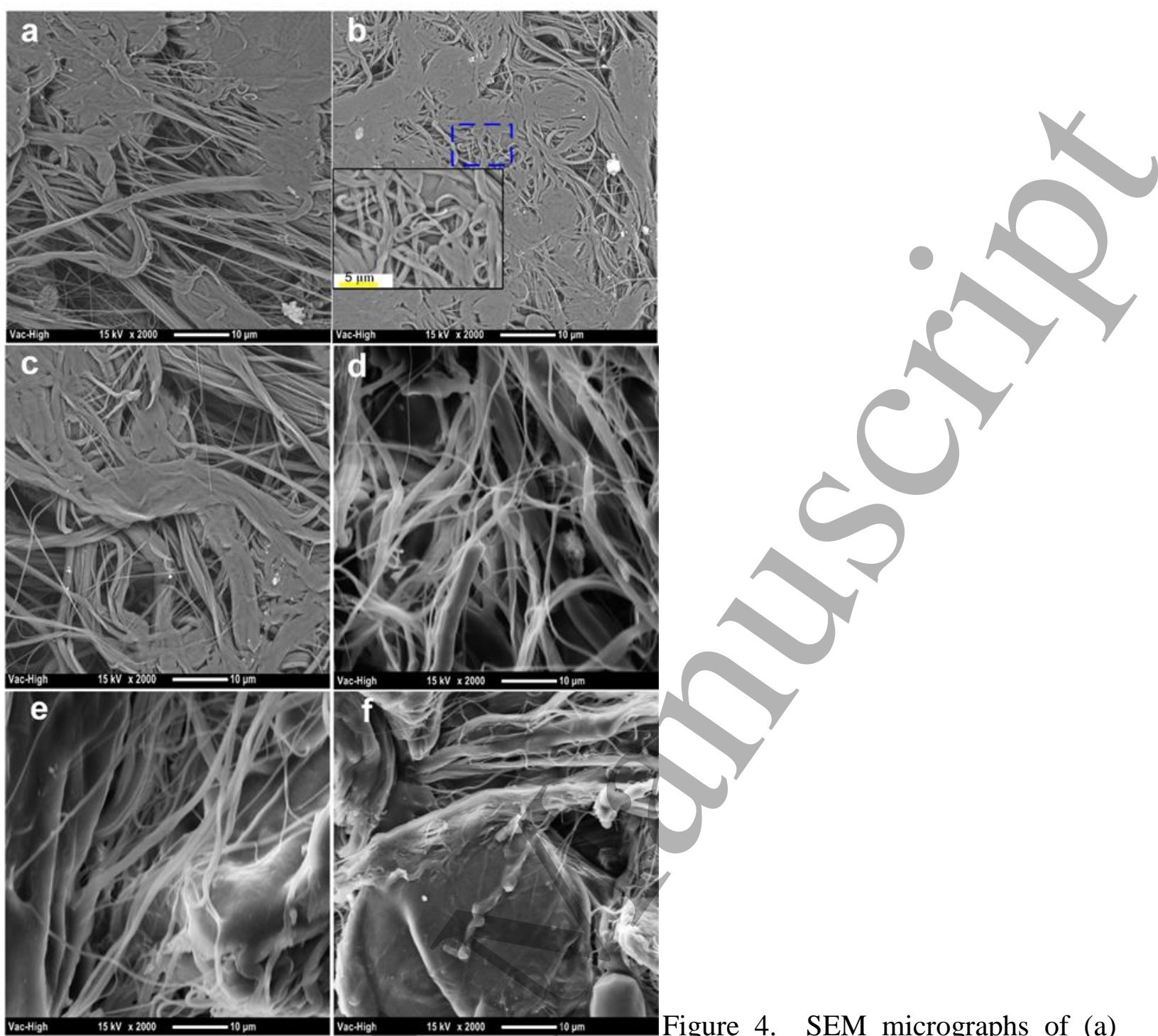

bottom surface, (b) top surface, (c) wall surface, (d) cross-section of plain PCL assembled 3D fibrous scaffold, (e) and (f) cross-section of 5 and $8 \mathrm{wt} . \% \mathrm{Mg}$ particles loading within assembled 3D fibrous scaffold respectively. Inset in panel (b) shows a higher magnification of selected dashed blue box. Panels (a), (b) and (c) illustrate the contact surfaces to the lower and upper punch and mold wall. 

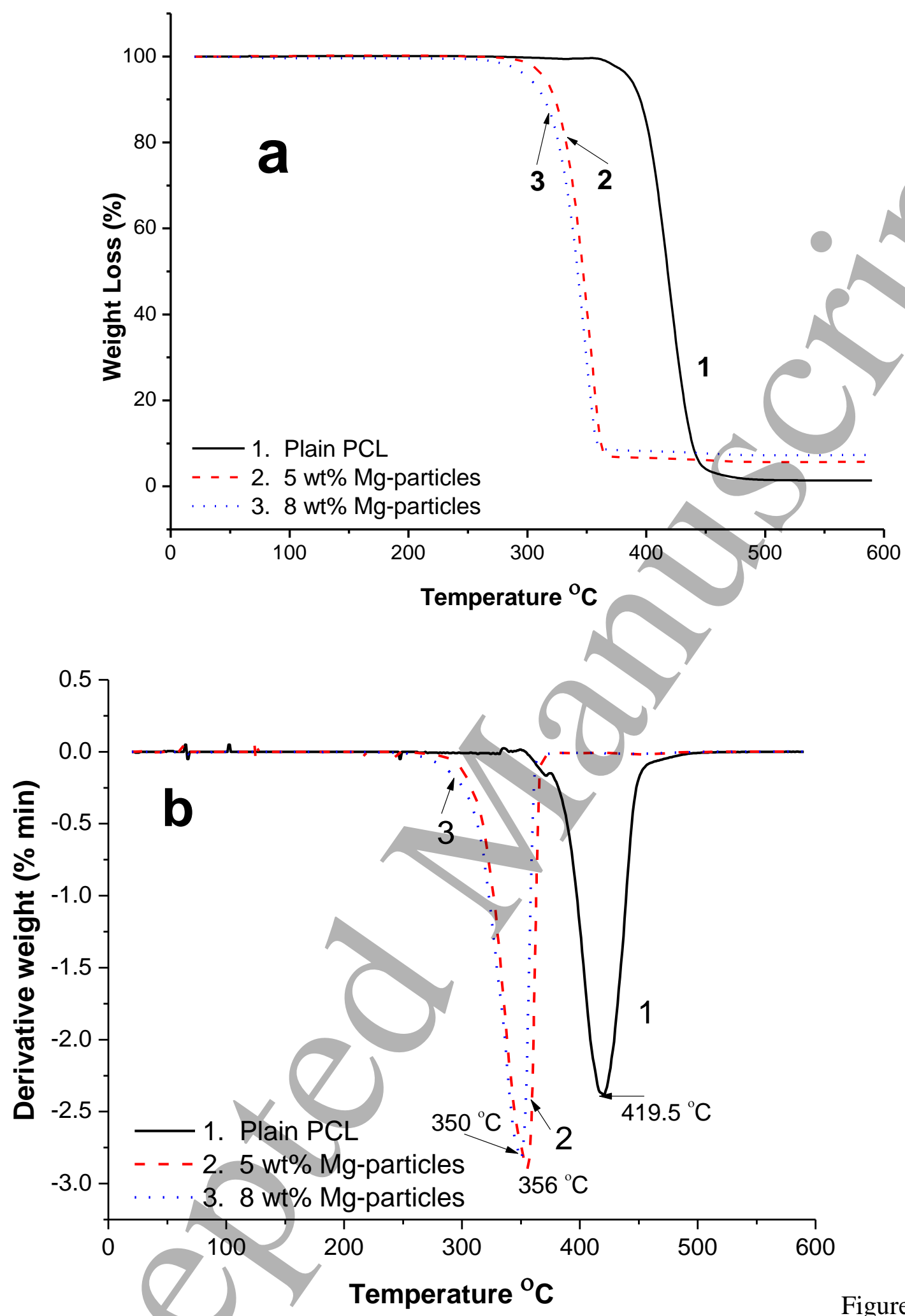

Figure 5. (A)

TGA and (B) DTA curves of fabricated 3-D fibrous scaffolds. 

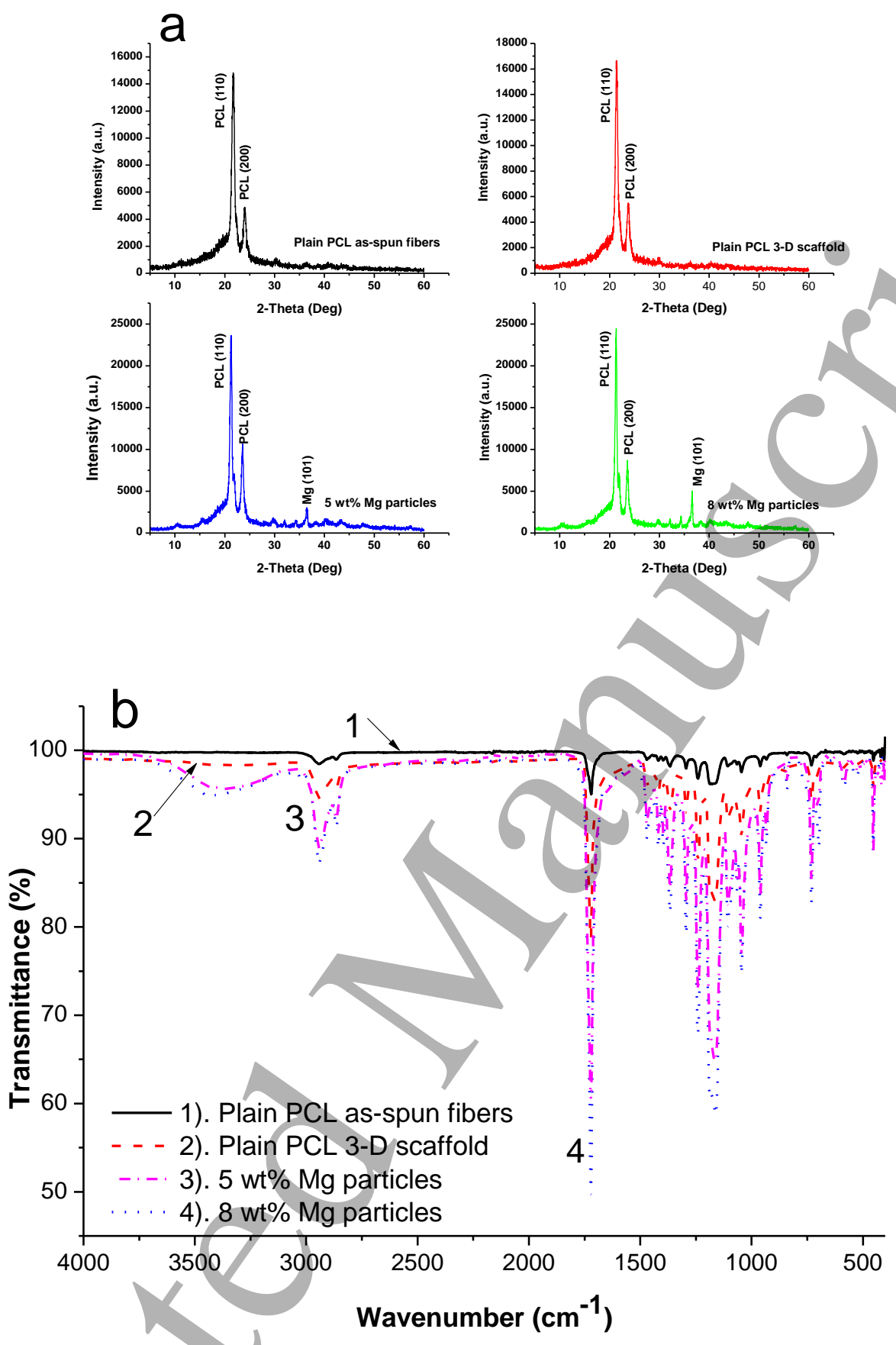

Figure 6. (a) XRD and (b) FTIR profiles of of fabricated 3-D fibrous scaffolds. 


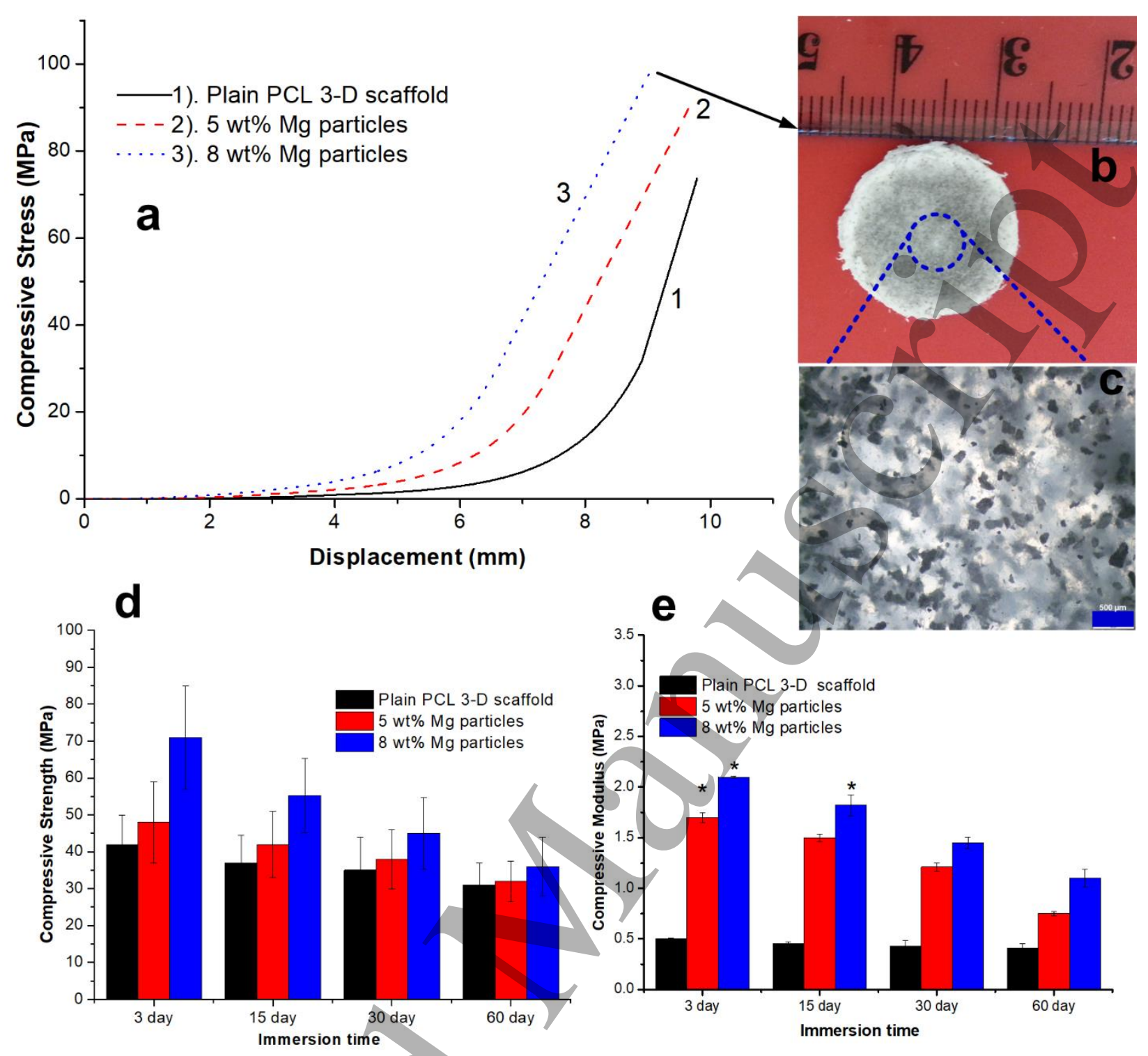

Figure 7. (a) Typical stress-strain curves of pristine PCL and PCL/Mg composite 3D fibrous scaffolds under compression loading. As strain increases, the 3D pores of the scaffolds are crushed and undergo a densification process. When the fibers are crushed, the stress level rises quickly. The curves show that the material changes its mechanical behavior with its composition.

(b and c) 2D images of composite scaffold obtained after the compression test. (d) Compressive strength and (e) compressive modulus of the same scaffolds after immersion in PBS media for $3,15,30$ and 60 days. 

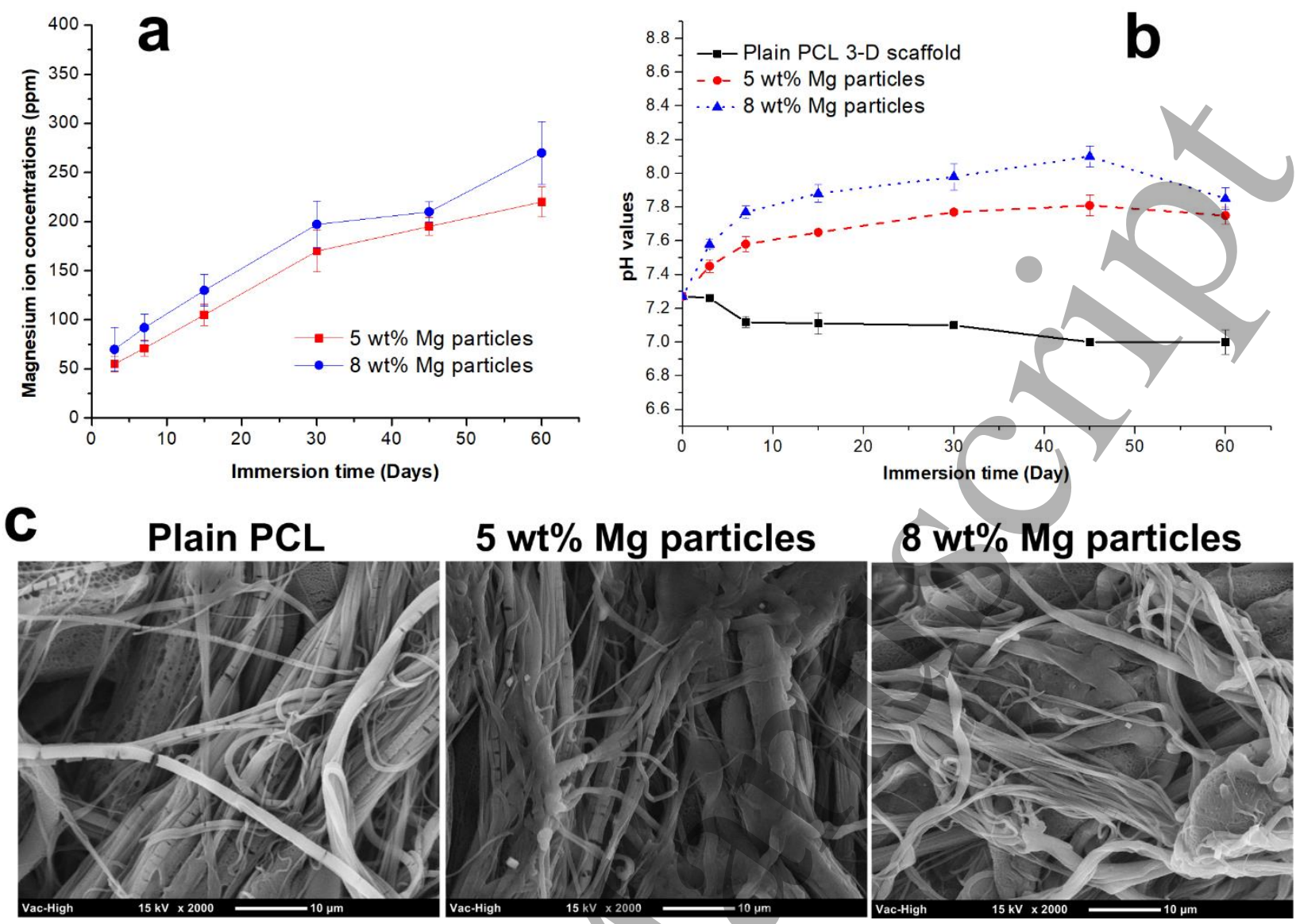

\section{$5 \mathrm{wt} \% \mathrm{Mg}$ particles}

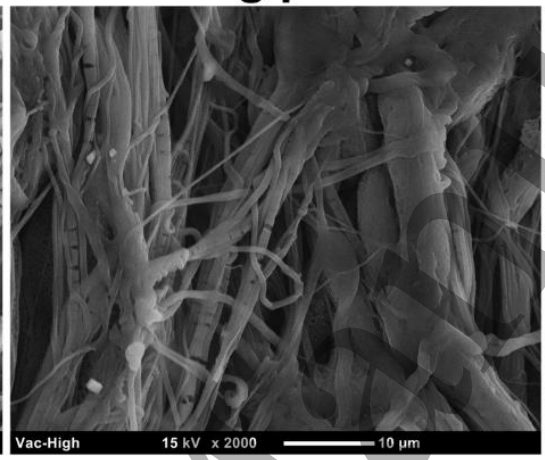

$8 \mathrm{wt} \% \mathrm{Mg}$ particles

Figure 8. (a) Magnesium ion release from PCL/Mg composites over time. (b) $\mathrm{pH}$ of the immersion extract from plain PCL and PCL/Mg composites over time. The $\mathrm{pH}$ values of the composite extracts increased steadily whereas the $\mathrm{pH}$ value of pure PCL decreased upon 2 months degradation. (c) SEM micrographs of plain and composite scaffolds after immersion for 2 months in PBS media. 


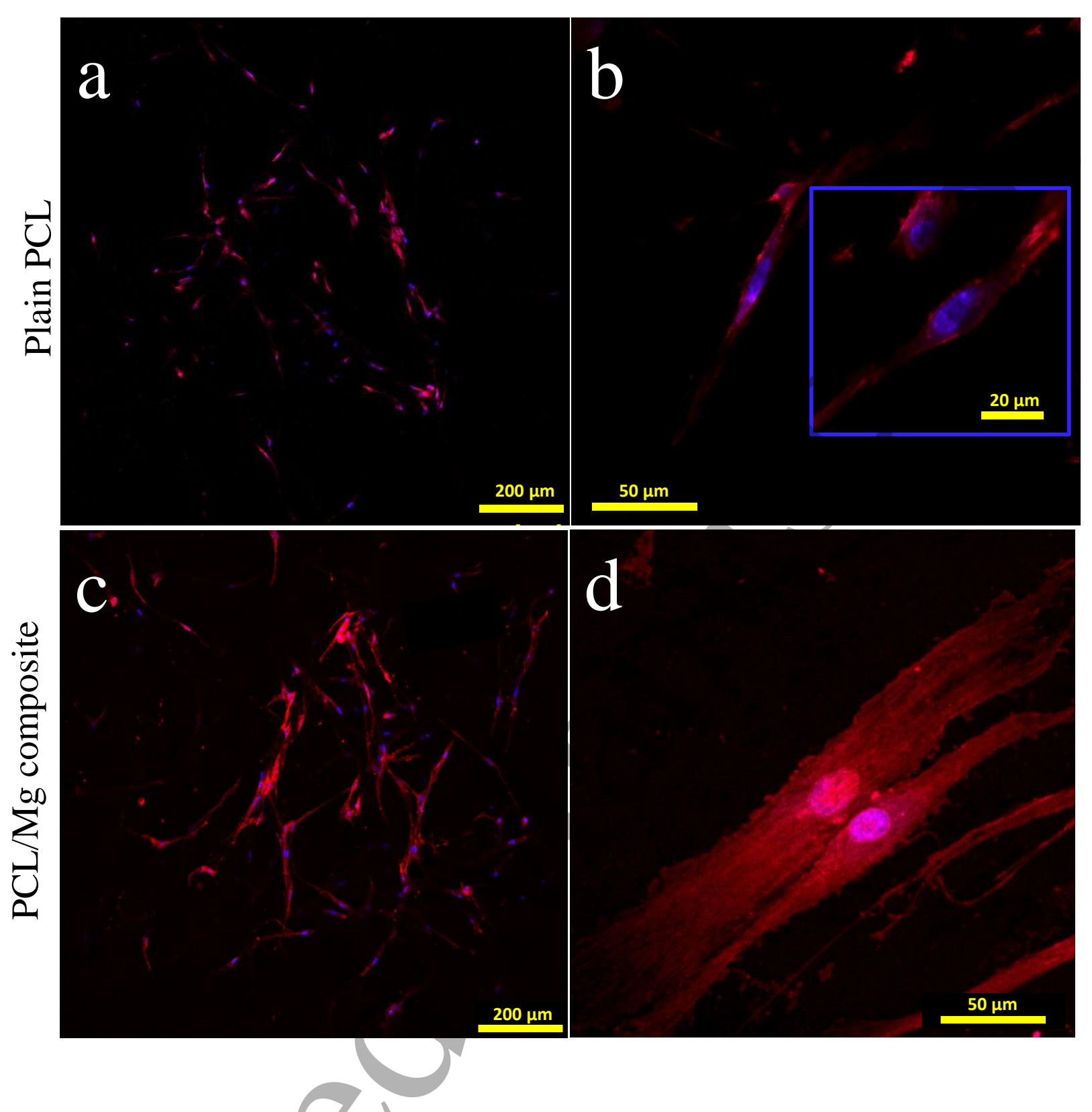

Figure 9. Confocal laser scanning microscopy images of (a \& c) osteoblast cell distribution on the assembled scaffolds; actin filaments (red), nuclei (blue). (b \& d) Higher magnification images of single cell morphology of alveolar-bone derived human osteoblasts cultured for 1 day on plain PCL and PCL/Mg composite assembled 3D fibrous scaffolds. Maximum intensity Z-projections on the $3 \mathrm{D}$ assembled fibrous scaffolds are shown. 


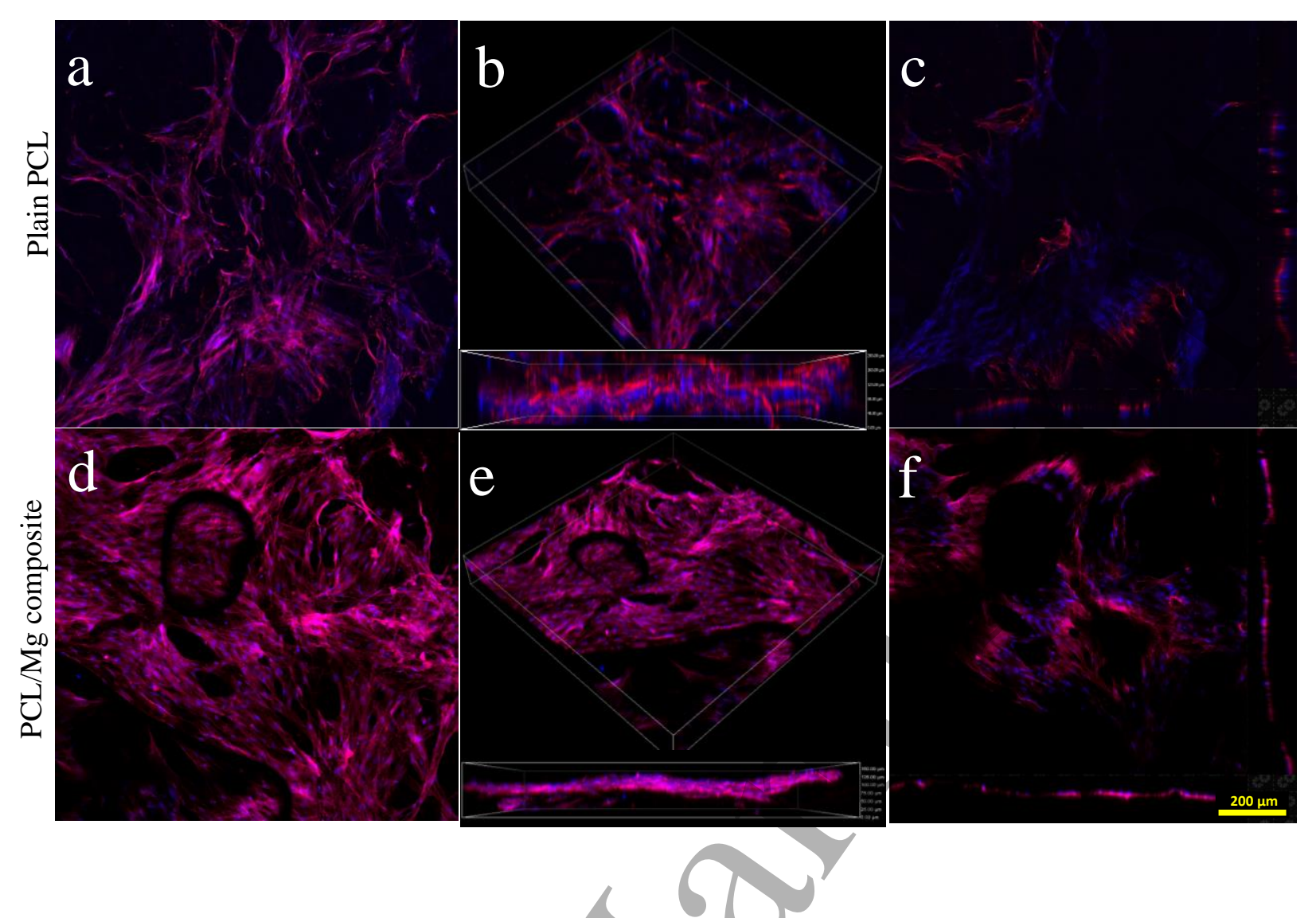

Figure 10. (a and d) Osteoblast spreading, morphology and distribution. Cell nuclei were labeled with DAPI and actin was labeled with Alexa Fluor 546 phalloidin; (b \& e) 3D view of a confocal Z-stack rotated in 3D space to show how osteoblasts have migrated into the scaffold. (c and f) Osteoblast distribution through the entire scaffold structure after 7 days culture. Insets of $\mathrm{b}$ and e show cross-sectional views $(x+)$ of the 3D Z-stack. Projected and cross-sectional views of the scaffold suggests good cell distribution in the $\mathrm{z}$ vertical direction on the $3 \mathrm{D}$ assembled scaffolds. Average cell infiltration depth was $145 \pm 45 \mu \mathrm{m}$ on plain PCL and $125 \pm 36$ $\mu \mathrm{m}$ for PCL/Mg composite assembled 3D fibrous scaffolds. (For interpretation of the references to color in this figure legend, the reader is referred to the web version of this article.) 

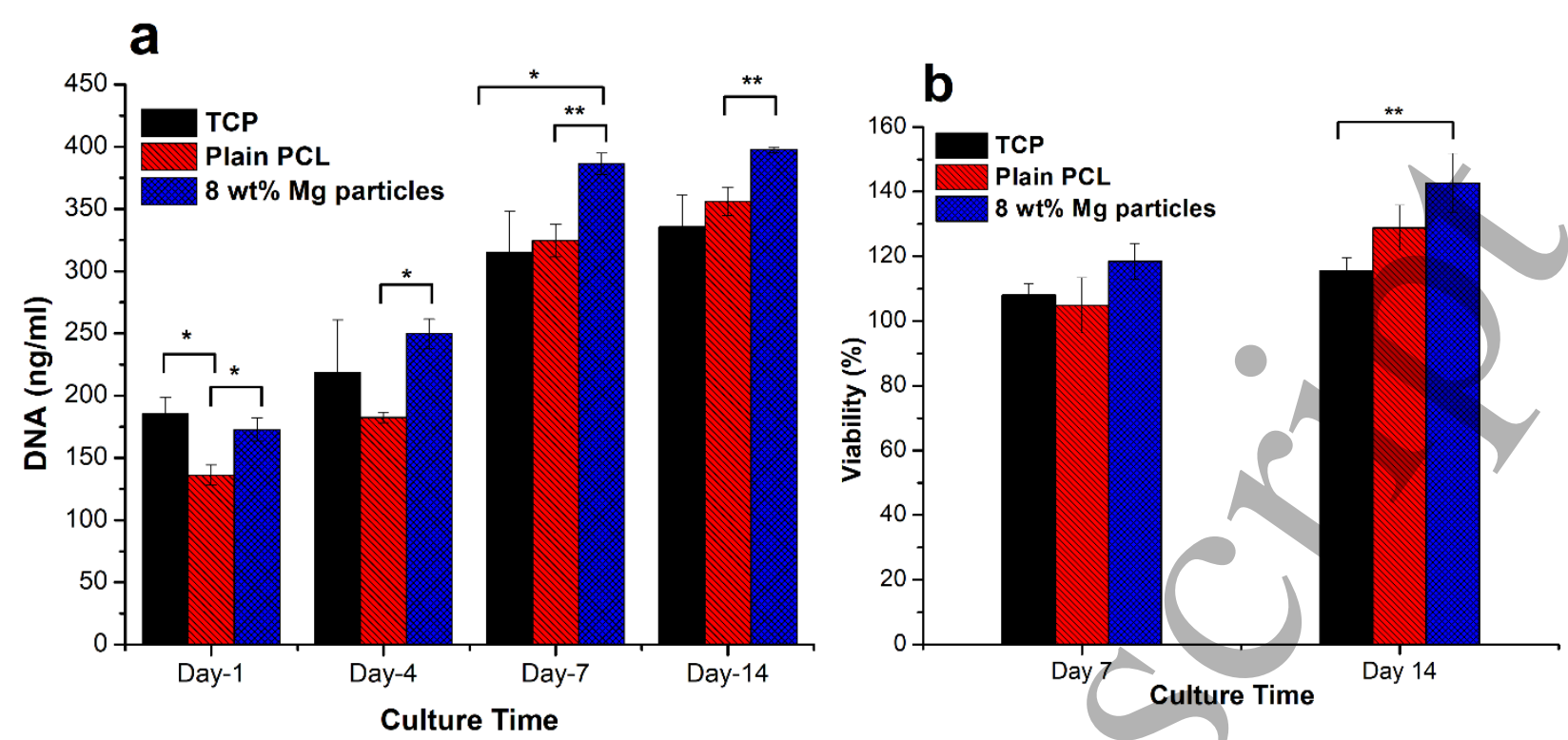

Figure 11. (a) Picogreen DNA assay and (b) Alamr blue assay of osteoblast cells grown on plain PCL, PCL/Mg composites 3D assembled scaffolds and control tissue plastic plastic (TCP). Significant differences in cell density (DNA quantification) and metabolic activity (Alamr blue assay) were shown with culture on the 3D assermbled scaffolds compared to culture on the plain PCL and/or TCP control $(* \mathrm{p}<0.05$, and $* * p<0.01) n=3$, for the picogreen assay and $n=6$ for metabolic activity assessment. 